\title{
Activation of polarized cell growth by inhibition of cell polarity
}

Marco Geymonat $^{1,2}$, Anatole Chessel ${ }^{1,2,}$, James Dodgson ${ }^{1,2}$, Hannah Punter ${ }^{1}$, Felix Horns $^{2, \dagger}$, Attila Csikász Nagy ${ }^{3,4,5}$, Rafael Edgardo Carazo Salas ${ }^{1,2^{*}}$

${ }^{1}$ Pharmacology \& Genetics Departments, University of Cambridge, Downing Street, Cambridge, CB2 3EH, United Kingdom.

${ }^{2}$ The Gurdon Institute, University of Cambridge, Tennis Court Road, Cambridge, CB2 1QN, United Kingdom.

${ }^{3}$ Department of Computational Biology, Research and Innovation Centre, Fondazione Edmund Mach, San Michele all'Adige, 38010, Italy.

${ }^{4}$ Pázmány Péter Catholic University, Faculty of Information Technology and Bionics, 1083 Budapest, Hungary.

5 The Randall Division of Cell and Molecular Biophysics and Institute of Mathematical and Molecular Biomedicine, King's College London, SE1 1UL, United Kingdom.

*Correspondence to: rc16805@bristol.ac.uk

Current address: "School of Cellular and Molecular Medicine, University of Bristol, Bristol, BS81TD, UK. `Biophysics Graduate Program, Stanford University, Stanford, CA 94305, USA. ${ }^{\S}$ LOB, Ecole Polytechnique, CNRS, INSERM, Université ParisSaclay, 91128 Palaiseau Cedex, France.

Running title: Activation of polarized growth by inhibition of polarity 
1 Abstract

2 A key feature of cells is the capacity to activate new functional polarized domains

3 contemporaneously to pre-existing ones. How cells accomplish this is not clear.

4 Here, we show that in fission yeast inhibition of cell polarity at pre-existing

5 domains of polarized cell growth is required to activate new growth. This

6 inhibition is mediated by the ERM-related polarity factor Tea3, which

7 antagonizes the activation of the Rho-GTPase Cdc42 by its co-factor Scd2. We

8 demonstrate that Tea3 acts in a phosphorylation-dependent manner controlled

9 by the PAK kinase Shk1 and that, like Scd2, Tea3 is direct substrate of Shk1.

10 Importantly, we show that Tea3 and Scd2 compete for their binding to Shk1,

11 indicating that their biochemical competition for Shk1 underpins their

12 antagonistic roles in controlling polarity. Thus, by preventing pre-existing

13 growth domains from becoming overpowering, Tea3 allows cells to redistribute

14 their polarity-activating machinery to prospective sites and control their timing

15 of activation. 


\section{Main text}

\section{Introduction}

Countless aspects of cellular function rely on the capacity of cells to activate multiple functionalized domains at their cortex simultaneously. This phenomenon underlies cellular behaviors such as migration, differentiation or chemotaxis, but how cells assemble new functional cell polarity areas in the presence of pre-existing ones is not fully understood. The cylindrically-shaped fission yeast (Schizosaccharomyces pombe) recapitulates this conundrum. Newly born $S$. pombe cells grow in a monopolar fashion only from their pre-existing 'old end' (OE), which was inherited from their mother at cell division. This old end becomes growth competent after an event called 'old end take off' (OETO). The 'new end' (NE) formed at the site of division during septation, albeit polarized, is functionally incapable of growing until later in the cell cycle when "new end take off" (NETO (Mitchison and Nurse, 1985)) happens and cells switch on bipolar growth for the remainder of the cycle. The NETO bipolar growth switch involves a number of proteins (Huisman and Brunner, 2011), including: the Kelch-repeat factors Tea1 and Tea3, the Tea1-interactor Tea4 and the actin-interacting protein Bud6, which are polarity landmarks delivered to cell ends in a microtubule-dependent manner; the actin-nucleating Tea4-interacting formin For3, which in conjunction with the active Rho-like GTPase Cdc42 assembles an array of actin cables at the cell ends that directs there exocytosis; and the DYRK kinase Pom1, which contributes to confine active $\mathrm{Cdc} 42$ to cell ends by restricting the localization of the Cdc42 GTPase Activating Protein (GAP) Rga4 to the cell sides. 


\section{Results and Discussion}

Although the mechanistic contribution of most $S$. pombe polarity factors is wellstudied, much less is known about Tea3 - a protein distantly related to the ERM (Ezrin/Radixin/Moesin) protein family (Arellano et al., 2002). tea34 (tea3-deleted) cells are NETO defective, which has led to the suggestion that Tea3 is an activator of polarized growth (Arellano et al., 2002; Niccoli et al., 2003), and looking at Tea3GFP revealed that as published (Arellano et al., 2002) the protein localizes both at the cell ends as well as at the septum, i.e. areas of the cell where growth occurs. However, on close inspection we found that Tea3's localization pattern anti-correlates conspicuously with that of polarized cell growth, much more than originally noted (Arellano et al., 2002). This was particularly obvious when we co-expressed Tea3GFP with the RFP-labelled $\beta$-glucan synthase Bgs4 (a marker of growing cell domains (Cortes et al., 2005)) and found that, though always present to some extent at cell ends, Tea3 anti-correlates with Bgs4 accumulation at the cortex throughout the entire cell cycle (Figure 1A left). Specifically, we found that Tea3 cortical enrichment: a) increases at the NE and decreases at the OE following OETO; b) drops at the NE following NETO; and c) rises again at both cell ends at septation (Figure 1A middle and right). In stark contrast with its earlier suggested role as an activator of polarity (Arellano et al., 2002), these observations suggested that Tea3 becomes enriched at inactive polarity areas and, therefore, that it could be an inhibitor of polarity.

To test this, we looked at the impact of tea3 deletion (knock-out) on the accumulation of the Cdc42-activating machinery at the cell cortex. The Rho-like GTPase Cdc42 and its GTP-loading co-factors Scd1 (a Cdc42 Guanosine Exchange Factor (GEF)) and 
$65 \mathrm{Scd} 2$ (a scaffold protein, co-activator of Scd1) are major regulators of polarized

66 growth in this species (Rincon et al., 2014), and the cortical abundances of GTP-

$67 \mathrm{Cdc} 42, \operatorname{Scd} 1$ and Scd2 quantitatively report on the level of polarity activity at cell

68 ends (Abenza et al., 2015; Bendezu et al., 2015; Das et al., 2012). Strikingly, when we

69 measured the levels of Scd1 and Scd2 at the cell cortex in tea3A monopolar cells, we

70 found that both $\mathrm{Cdc} 42$ co-factors become significantly enriched at OEs in tea3A cells

71 (Figures 1B-1C and Figure 1-figure supplement 1E-F). This enrichment was specific

72 to tea3A, as $\mathrm{Scd} 1 / \mathrm{Scd} 2 \mathrm{did}$ not become enriched at the OEs in monopolar wild-type

73 cells or in the cells of another monopolar mutant $\operatorname{rgfl\Delta }$ (Figure 1B, right quantitation;

74 Rgf1 is a Rho1-GEF (Garcia et al., 2006)), and it was specific to Scd1/Scd2, as Bgs4

75 (itself another positive regulator of polarized growth) did not become enriched at OEs in monopolar tea3 4 cells (Figure 1D). These data demonstrate that in the absence of Tea3 cell polarity activation at the cortex increases in cells, and indicates therefore that in wild-type cells Tea3's role is in fact to suppress the enrichment of Cdc42 activators at the cortex and to inhibit $\mathrm{Cdc} 42$ activity and cell polarity.

How could Tea3, an inhibitor of polarity, activate polarized growth at NETO?

One possibility would be if, by being enriched at non-growing ends (NEs) before NETO, Tea3 could maintain polarity inhibited there until a signal(s) would lead to its delocalization and, consequently, to the activation of polarized growth at the NE. A prediction of this would be that NETO could only happen once Tea3 becomes displaced from the NE. Therefore we looked in time-lapse sequences whether Tea3 displacement precedes, is coincident with or follows NETO (as assessed by de novo RFP-Bgs4 recruitment to the NE; time-lapse interval: $10 \mathrm{~min}$ ). We found that Tea3 
113 1-figure supplement $1 \mathrm{C}$ ). (Note: the partial rescue is likely due to the fact that Tea3 depletion from the NE never precedes NETO (0/11 cells followed by time-lapse) and instead either coincides with NETO (7/11 cells) or follows it $(4 / 11$ cells). This suggests that, although we cannot exclude the possibility that Tea3 detachment from the NE could be involved in NETO, if indeed Tea3 inhibits polarity at the NE that inhibition is relieved by NETO rather than causative for NETO. We conclude that the NETO switch likely does not depend on Tea3's function at the NE.

Could NETO depend on Tea3's function at the OE (i.e. the pre-existing, actively growing end)? To test this possibility, we sought to deplete Tea3 from the OE. We did this by forcing Tea3 to dimerize with the Cdc42 GTPase Activating Protein Rga4 (normally excluded from actively growing OEs) or with the Weel regulating kinase Cdr2 (confined to the cell middle), using the GFP-GBP (GFP Binding Protein) system (Rothbauer et al., 2008). Co-expression of Rga4-GFP with Tea3-GBP led Tea3 to become depleted from the growing end and both proteins to become enriched at the non-growing end in interphase cells (Figure 1E and Figure 1-figure supplement 1A). This led to a large increase in the percentage of monopolar, NETO-defective cells (Figure 1F and Figure 1-figure supplement 1B). We then co-expressed Cdr2-GFP with Tea3-GBP and found that Tea3 became depleted from both the growing and nongrowing ends (Figure 1E and Figure 1-figure supplement 1A), and that this led equally to a large increase in monopolar NETO-defective cells (Figure 1F). Importantly, in both cases additional co-expression of untagged Tea3 partially rescued bipolarity (Figure 1F and Figure 1-figure supplement 1D) without affecting the level of Rga4-GFP or Cdr2-GFP, and hence of Tea3-GBP, at the non-growing end (Figure

114 makes clusters in cells (Dodgson et al., 2013), and has the capacity to self-interact 
115 ((Snaith et al., 2005) and Figure 5-figure supplement 1A); therefore it is highly likely

116 that part of the untagged Tea3 interacts with Tea3-GBP and is delocalized from the

117 growth end, and hence cannot fully rescue the NETO defect observed upon co-

118 expression with Rga4-GFP/Cdr2-GFP.) Taken together, these results imply that Tea3

119 depletion from the growing end impairs NETO, and therefore that the NETO-

120 controlling function of Tea3 is most likely to inhibit Cdc42-mediated cell polarity at

121 the growing OE.

123 How then could Tea3 control Cdc42 activity? It has been shown that the function of

124 many ERMs and related proteins is controlled by phosphorylation (Fievet et al., 2004;

125 Hirao et al., 1996; Kissil et al., 2002; Nakamura et al., 1995; Pietromonaco et al., 126 1998; Yonemura et al., 2002) and Tea3 itself is predicted to be a phospho-protein

127 (Beltrao et al., 2009; Carpy et al., 2014; Wilson-Grady et al., 2008). Hence, we

128 reasoned that investigating Tea3's phospho-regulation in vivo could help clarify its

129 function. Immuno-precipitation of Tea3-GFP from wild-type cells revealed one band

130 by Western blot that migrated faster after treatment with lambda phosphatase (Figure

$1312 \mathrm{~A}$ lanes 1 and 2), demonstrating that Tea3 is phosphorylated in vivo, as predicted.

132 Tea3 phosphorylation was observed in lysates from cdc10-129 (G1 arrested) and

$133 c d c 25-22$ (G2 arrested) cells, indicating that it is not cell cycle dependent in any

134 obvious manner (Figure 2A lanes 3 to 6 and Figure 2-figure supplement 1).

135 Interestingly, it was disrupted in cells lacking Mod5, a prenylated protein which 136 concentrates at cell ends and anchors Tea3 cortically at the membrane (Snaith et al.,

137 2005; Snaith and Sawin, 2003) (Figure 2B left panel). Furthermore, we found the

138 phosphorylation to be specifically dependent on the polarity-linked PAK kinases Shk1

139 and Nak1 (Figure 2C), which also localize at cell ends (Matsuyama et al., 2006). 
140 These observations imply that Tea3's phosphorylation is dependent on its cortical

141 anchoring and might take place cortically within cells. Six phosphorylation sites have

142 been found at the Tea3 C-terminus (Beltrao et al., 2009; Carpy et al., 2014; Wilson-

143 Grady et al., 2008) and one of them (position 1045) is a putative PAK consensus site,

144 KRLS (Knaus et al., 1991), similar to the one found in the ERM-related factor Merlin

145 (position 518) and phosphorylated in vivo by PAK2 (Kissil et al., 2002). In order to

146 investigate the role of phosphorylation, we generated a phospho-impaired Tea3

147 mutated in all six sites (Tea3-6A-GFP; Figure 2B right panel). Interestingly, while

148 Tea3-6A-GFP localized normally through the cell cycle (Figure 2D and Figure 2-

149 figure supplement 2) we found that it induces a stark defect in NETO identical to that 150 observed in tea3A cells (Figure 2E-2F). Therefore, Tea3's PAK-dependent

151 phosphorylation is crucial to its NETO-regulating function.

153 As the PAK kinase Shk1 has been shown to interact directly with Scd2, and by 154 complexing with Scd2 it has been hypothesized to positively control Cdc42 activity 155 (Bendezu and Martin, 2012; Chang et al., 1999), we surmised that Shk1 might be the 156 relevant kinase at play and that it might interact directly with Tea3 as well. To test 157 that, we expressed and purified Tea3 and Shk1, and tested whether the pure proteins 158 interact. To our good surprise, we found not only that the proteins interact in vitro 159 (Figure 3A) but also that Shk1 phosphorylates Tea3 directly (Figure 3B). Given that 160 Tea3 suppresses the cortical enrichment of Scd2 at OEs (Figure 1B), and that both 161 Tea3 and Scd2 are substrates of the kinase Shk1, we wondered if Tea3 might control 162 Scd2 enrichment at the cortex by competitively interacting with Shk1. To ask this, we 163 first expressed and purified Scd2 and we verified that it interacts with Shk1 directly in 164 our experimental conditions (Figure 3C), as reported (Chang et al., 1999). We then 
tested in vitro the binding affinity of Tea3 to Shk1 in absence or presence of excess

$166 \mathrm{Scd} 2$, and found that the binding affinity of Tea3 to Shk1 decreases to $30 \%$ in the

167 presence of $\mathrm{Scd} 2$, demonstrating that $\mathrm{Scd} 2$ can outcompete Tea3 (Figure 3D).

168 Reciprocally, we found that the binding affinity of Scd 2 to Shk1 decreases to $75 \%$ in

169 the presence of excess Tea3, demonstrating that Tea3 can also outcompete Scd2 in

170 vitro (Figure 3E). Interestingly, we found that Tea3 outcompetition of Scd2 only

171 occurs in presence of ATP (Figure 3E) and does not happen between excess Tea3-6A

172 and Scd2 (Figure 3F), suggesting a possible differential role for phosphorylation in

173 controlling Tea3-Shk1 versus Scd2-Shk1 interaction.

175 Taken together, these results demonstrate that Tea3 and Scd2 competitively interact

176 with Shk1 in vitro, suggesting they might also recapitulate features of that behaviour

177 in vivo. This was confirmed as follows.

179 A first prediction is that in tea3-6A cells, which phenocopy tea34's NETO delay

180 (Figure 2E-2F), Scd2 should also become enriched at the OE cell cortex in monopolar

181 cells, given that in vitro Tea3-6A cannot outcompete Scd2-Shk1 interaction (Figure

$1823 \mathrm{~F})$. We found that indeed Scd2 becomes significantly enriched at OEs in those cells

183 like in tea34 cells and as observed in orb2-34 cells (Das et al., 2012) (orb2-34 is a

184 shk1 mutant allele) (Figure 3G). A second prediction is that, just like Tea3 suppresses

185 Scd2 enrichment at the OE cell cortex (Figure 1B), Scd2 should reciprocally also

186 suppress Tea3 enrichment at the OE cortex. As predicted, we found that indeed in

$187 s c d 2 \Delta$ cells Tea3 becomes cortically enriched (Figure $3 \mathrm{H}$ ). A third prediction is that it

188 should be possible to observe a differential binding affinity of Tea3 or Scd2 for Shk1

189 in vivo, in presence versus absence of the competitor. In agreement with this 
190 prediction, we found that whilst an interaction of Shk1 with Tea3 was undetectable in

191 vivo in wild-type cells, in $s c d 2 \Delta$ cells that interaction was readily detected (Figure

192 3I). These data demonstrate that in vivo Tea3 and Scd2 competitively bind their 193 common kinase Shk1.

195 Tea3's Shk1-dependent antagonism with $\mathrm{Scd} 2$ and its Cdc42 negative regulatory

196 function are reminiscent of negative feedbacks shown to be required for fuelling 197 oscillatory behaviour of Cdc42 activity at the cell cortex, in both budding and fission 198 yeast cells. In S. cerevisiae, it was recently demonstrated that a negative feedback 199 provided by the PAK kinase Cla4 inhibits the catalytic activity of the Cdc42 GEF 200 Cdc24 (Kuo et al., 2014). In S. pombe the existence of a negative feedback required 201 for NETO was postulated based on mathematical modelling and, interestingly, it was 202 also suggested to involve the similar PAK kinase Shk1 (Das et al., 2012).

204 We wondered if Tea3 is part of that feedback mechanism and asked whether, like 205 GTP-Cdc42, its level fluctuates/oscillates at cell ends. Hence, we co-expressed CRIB$206 \mathrm{mCh}$ (an indirect reporter of GTP-Cdc42) and Tea3-GFP in cells, imaged them by 207 time-lapse microscopy and we quantitated the fluctuation of their fluorescence 208 intensity at cell ends by automated image analysis. As previously reported, we 209 observed that about half of wild-type cells display CRIB oscillations between both 210 cell ends (period 535.5 \pm 207 seconds, $n=202$ tracked cells; Figs. 4A top and 4B). 211 Conspicuously, we found that Tea3 also oscillates between the cell ends (period $212792 \pm 297$ seconds, n=202 tracked cells; Figs. 4A bottom and 4C) in approximately 213 half of wild-type cells, suggesting that Tea3 could indeed be linked to the GTP-Cdc42 214 oscillation gearbox. To test this directly, we quantitated CRIB oscillations in tea3A 
215 cells and found that in those cells their period of oscillation is $30 \%$ longer than in

216 wild-type cells (Figure 4D). Interestingly, Shk1 suppression has been shown to affect

217 GTP-Cdc42 oscillations similarly to Tea3 (Das et al., 2012). This result demonstrates

218 that Tea3 participates mechanistically in the control of GTP-Cdc42 oscillations in

219 cells, and suggests a key Shk1-mediated role for Tea3 in the negative feedback loop

220 that drives these oscillations. Lastly, we asked whether, despite their difference in

221 period of oscillation, Tea3 and GTP-Cdc42 oscillations are linked. By measuring the

222 cross-correlation between the two oscillations we found that Tea3 and GTP-Cdc42

223 oscillate within a phase difference of $\pm \pi / 2$ and are therefore linked (Figure 4E).

224 Taken together, our results demonstrate that (although likely not the only component

225 (Das et al., 2015)) Tea3 is integral to the negative feedback mechanism that controls

226 the GTP-Cdc42 oscillations important for the bipolar switch in fission yeast.

228 It is interesting to note that though Tea3 negatively regulates Cdc42, GTP-Cdc42 and

229 Tea3 oscillate between the two cell ends with distinct periods. Whilst these two

230 findings could seem superficially at odds with each other, it is important to point out

231 that both proteins are imperfect, stochastic oscillators. This is evident from the

232 original publication describing GTP-Cdc42's oscillatory behaviour in fission yeast

233 (Das et al., 2012), where only half of cells were seen to manifest clear oscillations.

234 Likewise, it can be seen from our results that both oscillators are imperfect and

235 somewhat erratic (Figs. 4A-4C), and similarly we could only detect Tea3's oscillation

236 in half of cells. Because of this stochastic nature, it follows that an exact relationship

237 between their oscillatory behaviours is probably impossible in practice. Furthermore,

238 we note that the whole system is likely not entirely described by Tea3 and GTP-

239 Cdc42, but may include other stochastically-oscillating players (see for example (Das 
240 et al., 2015)), which could cause counter-intuitive differences in the Tea3 and GTP-

241 Cdc42 periods. Despite this, we can affirm that there is a link between both factor's 242 oscillations, i.e. their phase difference is not random but constrained between $\pm \pi / 2$, 243 which demonstrates that GTP-Cdc42 and Tea3 oscillations are part of the same 244 machinery.

246 Finally, we wondered if Tea3's polarity inhibitor function and its functional 247 antagonism with the polarity activator Scd2 might be sufficient to account for Tea3's 248 role in both regulating GTP-Cdc42 oscillations and controlling NETO. To test this, 249 we did a simplified one-dimensional mathematical model, where we sought to 250 recapitulate the Tea3-Scd2 antagonism by simulating a generic Cdc42 'activator'251 'inhibitor' pair of activities, freely diffusing but cortically localized and retained at 252 cell ends via interaction with microtubule-transported landmark proteins (Figure 5A; 253 see Materials and Methods) (Csikasz-Nagy et al., 2008). The model is based on an 254 earlier one dimensional reaction-diffusion model of cell polarity regulation (Csikasz255 Nagy et al., 2008), shown to match several aspects of fission yeast growth patterns 256 and used as the basis for other fission yeast polarity modelling efforts (Das et al., 257 2012; Thadani et al., 2011). Though based on Scd2 and Tea3, the activator and 258 inhibitor activities we simulated were intentionally kept generic both because of our 259 limited information on the Tea3-Shk1-Scd2 system and to make the least number of 260 assumptions about the morphogenetic properties at play. In the model, we assumed a 261 substrate-limited polarized growth activator (Act) and a substrate-limited inhibitor 262 (Inh), both of which collected cortically at cell ends in an autocatalytic fashion (ActC 263 and InhC, correspondingly). This is not an unrealistic assumption given that we had 264 previously found that polarity regulators in this species localize to cortical clusters 
265 likely generated by protein oligomerization (Dodgson et al., 2013) and that at least in

266 the case of Tea3 we found that it has the capacity to self-interact (Figure 5-figure 267 supplement 1A). Also, we assumed that Inh was a faster diffusing form of the 268 inhibitor that interferes with the autocatalytic activation of Act, and conversely that 269 ActC was a slower diffusing form of the activator that interferes with the autocatalytic 270 stabilization of Inh, closing onto a negative feedback loop (Figure 5A, dotted blunt 271 arrows) with a cross inhibition between fast- and slow-diffusing species. The 272 existence of slow (ActC, InhC) and fast (Act, Inh) diffusing forms of the activator and 273 inhibitor were based on our experimental observation that Scd2 and Tea3 diffuse 274 faster in the cytoplasm than at the cell end cortex (Figure 5-figure supplement 1B). 275 This difference in diffusion rates is a prerequisite for Turing-type pattern forming reactions (Goryachev and Pokhilko, 2008; Turing, 1952).

We then asked whether this simple activator-inhibitor in silico system is sufficient to recapitulate the major features of polarity activation observed in vivo.

281 In a 'wild-type' situation, when both the activator and inhibitor were present and 282 allowed to antagonize each other in silico, initially small monopolar cells - with the 283 activator concentrated at the $\mathrm{OE}$ and consequently the inhibitor concentrated at the 284 NE - grew and became bipolar - with both the activator and inhibitor present in both 285 ends - and this happened at a characteristic 'NETO' length (Figs. 5B and 5C), much 286 like what is observed in cells. We first tested what happens when the antagonism 287 between the activator and inhibitor are disrupted in silico. When the inhibitor was not 288 able to antagonize the activator, we found that the level of activator at the growing OE 289 of monopolar cells increased (Figure 5D), akin to the enrichment of Scd2/Scd1 
observed at the $\mathrm{OE}$ in monopolar tea3A cells (Figure 1B). Notably, this enhanced

291 enrichment of activator at the OE coincided with the cells undergoing NETO at a

292 much longer length (i.e. having a NETO delay; Figure 5D) like tea3A cells in vivo

293 (Figure 5E), demonstrating that polarity inhibition is required to properly activate new

294 growth areas. Reciprocally, when the activator was not able to antagonize the 295 inhibitor, we found that the inhibitor level at the OE of monopolar cells increased

296 (Figure 5F), similar to Tea3 at the OE in monopolar $s c d 2 \Delta$ cells (Figure 3H), and cells

297 became NETO defective like $s c d 2 \Delta$ cells. (Note: In the model this occurred because 298 in absence of ActC's effect the inhibitor accumulated at the OE in the clustered form, 299 which is incapable of inhibiting polarized growth there, leading to a NETO defect. In 300 vivo this effect could add to the delay caused by the reduced Cdc42 activation in the 301 absence of Scd2 (Kelly and Nurse, 2011), which was not explicitly modelled here.)

303 We then went on to test various perturbations on the NETO regulating system. We 304 first tested the effect in our in silico experiments of perturbations in the cluster 305 forming capabilities of Inh and Act. We found that those showed surprisingly 306 different results in the simulation: when the background polymerization rate of the 307 inhibitor was enhanced, we observed that this led to a predicted NETO delay (Figure $3085 \mathrm{G})$, whilst instead NETO was predicted to be advanced when polymerization of the 309 activator was enhanced (Figure 5H). Strikingly, when we mimicked this by enhancing 310 clustering of Tea3 or Scd2 in cells, by inducing oligomerization of the GFP-labelled 311 proteins using a previously published oligomer-inducing 3GBP construct (Dodgson et 312 al., 2013), we found that this led correspondingly to NETO delay or advance in vivo, 313 in agreement with the model's predictions (Figure 5I). 
315 Since our model contains a negative feedback loop (Figure 5A), which could induce

316 oscillations (Novak and Tyson, 2008) we then wondered if we could perturb the in

317 silico system to display oscillations in the level of the activator between both cell ends

318 ((Das et al., 2012) and Figure 4A). We found multiple ways to reach this (Figure 5J

319 and Figure 5-figure supplement 2 and see Materials and Methods). Strikingly, when

320 we decreased the effect of the inhibitor on the activator in the simulations (mimicking

321 tea3A cells as above (Figure 5D) we observed longer period oscillations in the

322 activator level at the cell ends, again just like in vivo (Figure 4D). We conclude that

323 the antagonism between the polarity activator and the inhibitor suffices to account for

324 all of the basic features of polarity activation observed in vivo and explains the

325 mechanistic role of Tea3's inhibitor role in controlling the activation of new polarized

326 growth at NETO.

328 In short, in monopolar cells competition of Tea3 and Scd2 for Shk1 binding leads to

329 inhibition of the Cdc42-activating module, allowing the polarity-activating machinery

330 to oscillate between cell ends and enabling a timely NETO switch (Figure 6). We

331 propose therefore that Tea3 is part of the Shk1-dependent negative feedback loop

332 previously found to control NETO (Das et al., 2012). By contrast, in absence of Tea3

333 GTP-Cdc42 oscillations are impaired and NETO is delayed. Thus, polarity inhibition

334 by Tea3 prevents growing cell ends from becoming overpowering (hyper-enriched)

335 with active $\mathrm{Cdc} 42$ and allows its redistribution to prospective growth sites, as required

336 for activating multiple areas of polarity at the cortex contemporaneously (Gierer and

337 Meinhard.H, 1972; Rupes et al., 1999; Turing, 1952) as well as control of the timing

338 of new growth activation. Interestingly, in this model Shk1 acts both at the level of

339 the positive feedback (thought to be mediated by Scd2 (Chang et al., 1999)) and at the 
340 level of the negative feedback (mediated by Tea3, shown here), underlying its central

341 role in controlling polarity and the NETO switch.

343 The C-terminal region of Tea3 has a homology with the C-terminal F-actin binding

344 domain present in the ERM-family proteins and Merlin (Arellano et al., 2002;

345 Bretscher et al., 2002). This domain in Merlin and Moesin is subjected to

346 phosphorylation by PAK-like kinases (Hipfner et al., 2004; Kissil et al., 2002) and is

347 essential for their activity. Since Merlin and Moesin have been shown to negatively

348 regulate Rac and Rho respectively (Shaw et al., 2001; Speck et al., 2003) and Tea3

349 inhibits Cdc42, we propose that there is functional homology between the carboxyl

350 terminal domain of Tea3 and the equivalent domains in the ERM-family proteins.

351 Interestingly, both Merlin and Moesin are at the same time regulators of and regulated

352 by small Rho-like GTPases, and it has been proposed that they are part of a feedback

353 loop important for Rho/Rac regulation (Neisch et al., 2013; Shaw et al., 2001; Speck

354 et al., 2003). We speculate that the role found here for Tea3 of activating polarized

355 growth by inhibiting polarity could extend to other ERM-related proteins. They could

356 equally control spatio-temporally cell polarity plasticity by modulating the tight

357 balance of Rho GTPase activities and turnover at the cortex. 


\section{Materials and Methods}

S. pombe strains and culture

361 The S. pombe strains used in this study are listed below. Media and general S. pombe

362 methods are as described (Moreno et al., 1991).

Plasmid construction

365 A SalI-NotI fragment containing Tea3 ORF and $500 \mathrm{bp}$ of promoter were amplified 366 and cloned into the integrative plasmid pJK148-GFP. This construction, integrated at 367 Leu1 locus, expressed a Tea3-GFP fusion protein that was able to complement the 368 monopolarity of a tea3 $\Delta$ strain. A plasmid expressing a phospho-mutant allele of Tea3 369 (Tea3-6A) where 6 serine residues $(950,984,1045,1058,1078$ and 1080) were 370 mutated in alanine was obtained by several rounds of mutagenic PCR. The mutagenic 371 oligos used were: 5' CGTAAGCTTGCTGAGGTACAAATTGCATTG 3' (S950A 372 shown in bold, underlined base indicates a silent mutation creating an HindIII site), 373 5'GCTTCCTCCGCTCCCTTGAGATCATACTTT3' (S984A shown in bold, 374 underlined base indicates a silent mutation eliminating an AflII site), 375 5'CATAAAAGACTTGCTGATGTTATCAACAGTCAGCAAAAATTTTTGTCTTT 376 GCCCCACAGGTATCTAAAGAT3' (S1045A and S1058A are shown in bold, 377 underlined base indicates a silent mutation eliminating an Bsu36I site), 378 5'CCGCGGGCGCATTTGCCGGCGAAGAAATGCGTGCA $\quad 3^{\prime} \quad$ (S1078A and 379 S1080A are shown in bold, underlined base indicates a silent mutation creating an 380 NaeI site). The PCR fragments were cloned into pJK148-Tea3-GFP using BglII-NotI 381 sites. Each mutation was confirmed by plasmid sequencing. 
383 In order to over-express Tea3, the nmt1 promoter $(1.1 \mathrm{~Kb})$ was amplified from pREP1

384 and cloned into a modified version of pJK148 using ApaI-NcoI sites creating pJK148-

385 nmt1. pJK148-nmt1-Tea3NT was obtained by cloning the first 1300 bp (containing a

386 unique EcoRI site) of Tea3 ORF into NcoI-NotI sites of pJK148-nmt1. An ApaI-

387 EcoRI fragment derived from pJK148-nmt1-Tea3NT was then cloned into pJK148-

388 Tea3GFP cut with the same enzymes. Plasmid expressing Tea3-mCherry or Tea3-

389 ProA-tag (i.e. protein A tag) were obtained by substituting GFP with amplified

390 mCherry or ProA-tag using NotI-XmaI restriction enzymes.

Lysate preparation and immunoblotting

393 To assess the phosphorylation status of Tea3 crude extract was obtained using the

394 TCA method described in (Foiani et al., 1994). Briefly, pelleted cells (25 $\mathrm{ml}$ at $\mathrm{OD}_{562}$

$395<0.8)$ were washed with $20 \%$ TCA, resuspended in $400 \mu 1$ of $20 \%$ TCA and broken 396 with glass beads using a Hybaid Ribolyser (3 cycle of 10 seconds with 3 minutes 397 intervals in ice). $800 \mu 1$ of TCA $5 \%$ was then added and the aqueous extract was spun 398 at $4000 \mathrm{rpm}$ for $10 \mathrm{~min}$. Supernatant was removed and the pellet was resuspended in $399100 \mu 1$ of $1 x$ Laemmli buffer plus $50 \mu 1$ of Tris $1 \mathrm{M}$. Tubes were then incubated at 95 $400{ }^{\circ} \mathrm{C}$ for 5 minutes and spun. Proteins were separated on $6 \%$ gels by SDS-PAGE. In 401 order to increase the migration difference between phosphorylated and non402 phosphorylated forms of Tea3, $5 \mu \mathrm{M}$ of Phos-tag (Wako) and $200 \mu \mathrm{M}$ of MnCl2 were 403 added to the gel as recommended by the manufacturer. To detect Tea3-GFP or 404 untagged Tea3 an anti-GFP antibody (Roche) at 1:1000 dilution or a polyclonal anti405 Tea3 antibody (kind gift of P. Nurse) at 1:2000 dilution were used. 
408 Cells expressing Tea3-GFP were cultivated overnight at $32{ }^{\circ} \mathrm{C}$ in yeast extract with

409 supplements (YES (Moreno et al., 1991); rich medium). Harvested by centrifugation

$410\left(\mathrm{OD}_{562}<0.8\right)$, washed once with cold extraction buffer $(\mathrm{EB}$ : Tris $40 \mathrm{mM} \mathrm{pH7.5,} \mathrm{NaCl}$

$411200 \mathrm{mM}$, KAcetate $50 \mathrm{mM}$, EDTA $1 \mathrm{mM}, \mathrm{MgCl}_{2} 2 \mathrm{mM}$, Triton X-100 0.2\%) and

412 resuspended in cold EB containing phosphatase inhibitors ( $\beta$-glycerophosphate 50

$413 \mathrm{mM}, \mathrm{NaF} 10 \mathrm{mM}$ and $\mathrm{NaO} 4 \mathrm{~V} 1 \mathrm{mM}$ ) and protease inhibitors (complete EDTA-free,

414 Roche and PMFS $1 \mathrm{mM}$ ). Cells were broken with glass beads using a Hybaid

415 Ribolyser (3 cycle of 10 seconds with 3 minutes intervals in ice). $5 \mathrm{mg}$ of total

416 proteins were mixed with $50 \mu \mathrm{l}$ of GFP-Trap magnetic beads and incubated at $4{ }^{\circ} \mathrm{C}$

417 for 2 hours. The beads were then washed 6 times with EB and resuspended in PMP

418 buffer containing $\mathrm{MnCl}_{2} 1 \mathrm{mM}$ (NEB). The beads were split in half and treated or not

419 with $3 \mu \mathrm{l}$ of $\lambda$-PPase (NEB) for $30 \mathrm{~min}$ at $30{ }^{\circ} \mathrm{C}$. Beads were washed twice with EB

420 and resuspended in Laemmli Buffer, heated at $95^{\circ} \mathrm{C}$ for 5 min and loaded on a gel.

For Shk1-Tea3 co-immunoprecipitation strains expressing GFP-Shk1 were cultivated

423 in YES medium at $32 \mathrm{C}$ and harvested in log phase of growth. Cells were re424 suspended in extraction buffer (Tris-HCl 50 mM pH7.5, NaCl 200 mM, Triton X-100 $4250.1 \%$, glycerol $10 \%$, DTT $2 \mathrm{mM}, \beta$-glycerophosphate $50 \mathrm{mM}, \mathrm{NaF} 10 \mathrm{mM}$ and $426 \mathrm{NaO} 4 \mathrm{~V} 1 \mathrm{mM}$, protease inhibitors (complete EDTA-free, Roche) and PMSF $1 \mathrm{mM}$ ) 427 and broken with glass beads using a Hybaid Ribolyser. $10 \mathrm{mg}$ of total proteins were 428 mixed with $50 \mu 1$ of GFP-Trap magnetic beads and incubated at $4{ }^{\circ} \mathrm{C}$ for 2 hours. The 429 beads were then washed 6 times with washing buffer (Tris- $\mathrm{HCl} 50 \mathrm{mM}, \mathrm{NaCl} 150$ $430 \mathrm{mM}$, Triton X-100 0.1\% and DTT $5 \mathrm{mM}$ ), resuspended in Laemmli Buffer, heated at $43195^{\circ} \mathrm{C}$ for $5 \mathrm{~min}$ and loaded on a gel. 


\section{Protein purification}

435 6His-Tea3, 6His-Tea3-6A, 6His-Scd2-3HA and GST-Shk1 were expressed in S. 436 cerevisiae (Geymonat et al., 2007). Ni-NTA agarose (Qiagen) and glutathione 437 sepharose 4B (GE Healthcare) were used to purify 6His and GST tagged proteins 438 respectively in accordance with the manufacturer protocols. Purified proteins were 439 dialyzed o/n at $4 \mathrm{C}$ in dialysis buffer (Tris- $\mathrm{HCl} 20 \mathrm{mM} \mathrm{pH} \mathrm{7.5,} \mathrm{NaCl} 150 \mathrm{mM}$, DTT 2 $440 \mathrm{mM}$, glycerol 10\%) and stored at $-80 \mathrm{C}$. Typical protein concentration was: for Tea3 441 and Tea3-6A, $0.5 \mu \mathrm{g} / \mu 1$, for Shk1, $0.7 \mu \mathrm{g} / \mu 1$ and for Scd2, $0.2 \mu \mathrm{g} / \mu 1$.

In vitro binding and competition

444 For in vitro Tea3/Shk1 or Scd2/Shk1 binding, strains M152 (expressing GST alone) 445 and M150 (expressing GST-Shk1) were induced for 6 hours. Cells were re-suspended 446 in breakage buffer (Bb: Tris- $\mathrm{HCl} 50 \mathrm{mM} \mathrm{pH}$ 7.5, $\mathrm{NaCl} 250 \mathrm{mM}$, Triton $\mathrm{X}-100$ 0.1\%, 447 DTT $5 \mathrm{mM}$, glycerol $10 \%$, EDTA $5 \mathrm{mM}$ and protease inhibitors (complete EDTA448 free, Roche and PMFS $1 \mathrm{mM})$ ). $10 \mathrm{mg}$ of crude extract from each strain was then 449 incubated with $70 \mu \mathrm{l}$ of glutathione beads slurry previously washed in $\mathrm{Bb}$ without 450 protease inhibitors for 2 hours at 4 C. Beads were then washed 6 times with washing 451 buffer (Wb: Tris-HCl $50 \mathrm{mM} \mathrm{pH} \mathrm{7.5,} \mathrm{NaCl} 250 \mathrm{mM}$, DTT $5 \mathrm{mM}$ and Triton $\mathrm{x}-100$ $4520.2 \%$ ) and one with binding buffer (Bb: Tris- $\mathrm{HCl} 30 \mathrm{mM} \mathrm{pH} \mathrm{7.5,} \mathrm{NaCl} 150 \mathrm{mM}$, $453 \mathrm{MgCl} 25 \mathrm{mM}$ and DTT $1 \mathrm{mM}$ ). Beads were resuspended in $100 \mu \mathrm{lof} \mathrm{Bb}$ and $5 \mu \mathrm{g}$ of 4546 His-Tea3 or 6 His-Scd2 were added to each tube. Tubes were incubated in agitation 455 for 1.5 hours at RT then spun and the beads were washed 4 times with washing buffer 456 (Wb2: Tris-Hcl $30 \mathrm{mM} \mathrm{pH} \mathrm{7.5,} \mathrm{NaCl} 150 \mathrm{mM}$ DTT 1mM and Triton X-100 0.1\%). 
457 Beads were then re-suspended in Laemli buffer and proteins analyzed by SDS-PAGE

458 followed by Western blotting.

460 For in vitro competition between Scd 2 and Tea3 for Shk1 binding, $250 \mu \mathrm{g}$ of crude

461 extract from strain M150 was used to purify GST-Shk1. GST-Shk1 beads were then 462 incubated in Bb containing $1 \mu \mathrm{g}$ of Tea3 alone or $1 \mu \mathrm{g}$ of Tea3 and $10 \mu \mathrm{g}$ of Scd2.

463 Beads were incubated in agitation for 1.5 hours at RT then spun and washed 4 times 464 with $\mathrm{Wb} 2$. Bound proteins were analyzed by SDS-PAGE followed by Western 465 blotting.

467 For in vitro competition between Tea3 and Scd2 for Shk1 binding, $250 \mu \mathrm{g}$ of crude 468 extract from strain M150 was used to purify GST-Shk1. GST-Shk1 beads were then 469 washed once in kinase buffer (Kb: Hepes $50 \mathrm{mM} \mathrm{pH} \mathrm{7.5,} \mathrm{MgCl2} 10 \mathrm{mM}, \mathrm{MnCl} 21$ $470 \mathrm{mM}$ and DTT $1 \mathrm{mM}$ ) and then re-suspended in $\mathrm{Kb}$ containing $1 \mu \mathrm{g}$ of Scd 2 alone in 471 presence or absence of $10 \mathrm{mM} \mathrm{ATP}$ or $1 \mu \mathrm{g}$ of Scd2 and $10 \mu \mathrm{g}$ of Tea3 in presence or 472 absence of $10 \mathrm{mM}$ ATP. Tubes were incubated for 45 minutes at $30 \mathrm{C}$ with occasional 473 agitation. Beads were washed 4 times with washing buffer (Wb3: Hepes $30 \mathrm{mM}$ $474 \mathrm{pH} 7.5, \mathrm{NaCl} 150 \mathrm{mM}, \mathrm{DTT} 1 \mathrm{mM}$ and Triton $\mathrm{X}-100$ 0.1\%) and proteins were 475 analyzed by SDS-PAGE followed by Western blotting.

478 In order to detect phosphorylated Tea3 species we used the Pro-Q Diamond 479 phopshoprotein gel stain (Invitrogen). Since the S. cerevisiae purified 6His-Tea3 is 480 slightly phosphorylated and interferes with the Pro-Q staining, Tea3 was pre-treated 481 with $\lambda$-PPase (NEB) and then re-purified. For the kinase assay $8 \mu \mathrm{g}$ of de- 
phosphorylated $6 \mathrm{His}-\mathrm{Tea} 3$ and $12 \mu \mathrm{g}$ of GST-Shk1 were mixed in Kb containing

$483 \mathrm{Na3O} 4 \mathrm{~V} 10 \mathrm{mM}$ in presence or absence of $10 \mathrm{mM}$ ATP. Kinase reaction was carried 484 out for 2 hours at $30 \mathrm{C}$ and then stopped by addition of Laemli buffer and incubation 485 at $99 \mathrm{C}$ for 5 minutes. Samples were analysed on SDS-PAGE and stained with Pro-Q 486 Diamond following manufacturer instructions.

489 S. pombe strains were grown at $32{ }^{\circ} \mathrm{C}$ to exponential growth and aliquots of $300 \mu \mathrm{l}$ 490 cells were mounted onto 1.5 coverslip glass-bottom plastic dishes (MatTek; P35G491 1.5-14-C) pre-coated with $10 \mu \mathrm{l} 1 \mathrm{mg} \mathrm{ml}^{-1}$ lectin. After a 30-min incubation, cells 492 unbound to the lectin-coated glass were removed by washing with medium, and 493 bound cells were kept in a final suspension of $3 \mathrm{ml}$ of medium. Imaging was 494 performed with a DeltaVision System (Applied Precision, USA), based on an 495 Olympus IX81 widefield microscope equipped with a CCD coolSNAP HQ ${ }^{2}$ camera 496 (Photometrix, USA), with a 60x/1.4 N.A. UPLSApo Oil objective. Images were captured and analyzed using SoftWoRx (Applied Precision). Unless otherwise stated, $498 \quad 18 \mathrm{z}$-stacks with a step of $0.3 \mu \mathrm{m}$ were filmed with transmitted light and FITC/TRITC 499 filters. Time-lapse images displayed and analyzed in Figure 4 were taken every 45 500 seconds for 45 minutes.

502 The monopolarity or bipolarity of exponentially growing cells was determined using 503 RFP-Bgs4 signal at one or both cell ends. Cell in septation or just after cytokinesis 504 (prior to OETO) were not considered. At least 100 cells per condition were analyzed. 505 Error bars represent standard deviation of 2 or 3 independent experiments. T-test was 506 used to compare sets of results. 
508 Quantification of GFP/RFP/mCherry signal was performed using Fiji

509 (http://fiji.sc/Fiji) software after background subtraction. For Tea3-WT and Tea3-6A

510 quantification at the cell ends the sum fluorescence of the cell area of $1.5 \mu \mathrm{m}$ from the

511 ends have been calculated.

$513 \quad$ Modelling

514 We extended the original model of Csikász-Nagy et al. (Csikasz-Nagy et al., 2008)

515 with an inhibitor that exists in cortical (InhC) and cytoplasmic (Inh) forms.

516 Specifically, the equations of the original Csikász-Nagy model were duplicated 517 leading to a system where both Act and a newly introduced Inh have similar 518 autocatalytic cortical binding reactions that are facilitated by a cortical landmark 519 protein $(u)$. The cortical activator $(A c t C$, originally named $f$ in the Csikász-Nagy 520 model) inhibits the autocatalytic cortical binding of the inhibitor, while the 521 cytoplasmic inhibitor inhibits the autocatalytic cortical binding of the activator

522 (Figure 5A). Thus the only difference between Act and Inh is in their dynamics and 523 the way they are wired, with the cortical form of Act competing with Inh's 524 autocatalysis while the cytoplasmic form of Inh competes with Act's autocatalysis.

525 This leads to a situation where a negative feedback loop is introduced in the system 526 ActC --| InhC --| Inh --| ActC. Such systems with three negative effects can induce 527 oscillations (Elowitz and Leibler, 2000) as shown in Figure 5-figure supplement 2.

529 The model is available as an annotated text file (Geymonat_model_final.ode, 530 Supplementary File) that can be run directly as an .ode file in in the XPPAUT 531 simulation software tool (http://www.math.pitt.edu/ bard/xpp/xpp.html). In the 
532 legends of Figure 5 we provide the parameter changes required to obtain each result

533 reported on Figure 5.

\section{Oscillation quantitations and automated microscopy analysis}

536 For the analysis of CRIB and Tea3 oscillations at cell ends, cells were segmented and 537 tracked automatically using in-house algorithms implemented in Matlab.

538 Photobleaching was corrected for each cell for each channel by assuming a constant

539 fluorescence. Mean fluorescence at each cell end for each channel was computed by

540 automatically defining the cell end geometrically, summing the pixels' greylevel

541 values and dividing by the area. To look at the actual fluorescence

542 fluctuations/oscillations, the continuous trend was removed using empirical mode

543 decomposition (Huang et al., 1998). Assessment of the oscillatory nature of the signal

544 was done in the same way as in (Das et al., 2012): autocorrelation of the signal at each

545 cell end was computed and a given cell end signal was deemed oscillating if, from its

546 starting point of 1 , the fluorescence dipped below zero and went back up above 0.2 ;

547 the period is then the time between two successive maxima. Interestingly, the Cdc42

548 periodicity of 9 min obtained in this study differs from that describerreported in (Das

549 et al., 2012), where a periodicity of 5 min was described. It is unclear exactly why the

550 oscillation period differs between that study and ours, therefore we can only

551 speculate. One plausible explanation could be the slight differences in the imaging

552 protocols. In particular the temperature used during the imaging experiments might

553 account for this discrepancy, given that all our imaging was done at a Room

554 Temperature of $\sim 21^{\circ} \mathrm{C}$ and that paper reports a temperature for all experiments of

$55525^{\circ} \mathrm{C}$. It is possible to imagine biochemical rates of Cdc42 GTPase cycle could be

556 temperature dependent. Other conditions, like optics and cell media, appear 
comparable and are hence less likely to account for that discrepancy. Importantly, the

558 oscillations of CRIB-mCherry and GFP-CRIB displayed the same period of $\sim 9 \mathrm{~min}$ in

559 our experimental conditions (not shown). Hence, it is likely differences in the

560 protocol, and not tagging, that underpins the discrepancy in the period of oscillation

561 between the (Das et al., 2012) study and ours.

563 For Figure 4E, the cross-correlation plot between the green and red channel was

564 computed for both cell ends for each cell and the density was plotted using kernel

565 density estimation.

567 To score cell length at NETO (Figure 5E) cells were automatically segmented and 568 tracked, and growth stage was assigned manually, as automated method lacked the 569 required sensitivity given the low number of tea3 $\triangle$ cells undergoing NETO.

$571 \quad$ Sample size \& statistical testing

572 Sample sizes are indicated in all figure legends. $\mathrm{p}$-values were calculated using the t573 test function in Microsoft Excel except in Figure 4D, where they were calculated 574 using a two sample Kolmogorov-Smirnov test in Matlab. 


\section{Author Contributions}

578 R.E.C.-S. conceived/led the project and R.E.C.-S. and M.G. designed the general

579 experimental and computational strategy. M.G. carried out all experimental yeast 580 work and imaging, with help from J.D. and H.P. A.C. carried out all quantitative 581 image processing and analysis, with help from F.H. A.C.N. carried out all in silico 582 modeling involved. R.E.C.-S. wrote the text with help from M.G. and other co583 authors.

\section{Acknowledgements}

586 We thank E. Piddini, J. Moseley, D. Lew, T. Finegan, J. Pines, K. Sawin, F. Verde, S. 587 Martin, J. Hayles, C. Bradshaw, F. Vaggi and the Carazo Salas group for help and 588 comments, M. Sato, P. Perez, D. Young. P. Nurse and S. Marcus for S. pombe strains, 589 P. Zegerman for kind gift of Phos-tag, A. Sossick and N. Lawrence for assistance with 590 imaging, and E. Piddini, D. Lew, J. Mata, J. Moseley and the Carazo Salas group for 591 critical reading of the manuscript. This work was supported by an European Research 592 Council (ERC) Starting Researcher Investigator Grant (R.E.C.-S.; SYSGRO), a 593 Human Frontier Science Program (HFSP) Young Investigator Grant (R.E.C.-S., A.C.594 N.; HFSP RGY0066/2009-C), a Biological Sciences Research Council (BBSRC) 595 Responsive Mode grant (R.E.C.-S.; BB/K006320/1) and an Isaac Newton Trust 596 research grant (R.E.C.-S.; 10.44(n)).

\section{Competing interests}

599 The authors declare no financial or non-financial competing interests. 
602

603

604

605

606

607

608

609

610

611 e1000134.

612

613

614

615

616

617

618

619 Carpy, A., Krug, K., Graf, S., Koch, A., Popic, S., Hauf, S., and Macek, B. (2014).

620 Absolute proteome and phosphoproteome dynamics during the cell cycle of fission

621 yeast. Mol Cell Proteomics.

622 Chang, E., Bartholomeusz, G., Pimental, R., Chen, J., Lai, H., Wang, L., Yang, P., 623 and Marcus, S. (1999). Direct binding and In vivo regulation of the fission yeast p21624 activated kinase shk1 by the SH3 domain protein scd2. Molecular and cellular biology 625

\section{References}

Abenza, J.F., Couturier, E., Dodgson, J., Dickmann, J., Chessel, A., Dumais, J., and Carazo Salas, R.E. (2015). Wall mechanics and exocytosis define the shape of growth domains in fission yeast. Nature communications 6,8400 .

Arellano, M., Niccoli, T., and Nurse, P. (2002). Tea3p is a cell end marker activating polarized growth in Schizosaccharomyces pombe. Curr Biol 12, 751-756.

Beltrao, P., Trinidad, J.C., Fiedler, D., Roguev, A., Lim, W.A., Shokat, K.M., Burlingame, A.L., and Krogan, N.J. (2009). Evolution of phosphoregulation: comparison of phosphorylation patterns across yeast species. PLoS biology 7, Bendezu, F.O., and Martin, S.G. (2012). Cdc42 oscillations in yeasts. Science signaling 5 , pe53.

Bendezu, F.O., Vincenzetti, V., Vavylonis, D., Wyss, R., Vogel, H., and Martin, S.G. (2015). Spontaneous Cdc42 polarization independent of GDI-mediated extraction and actin-based trafficking. PLoS biology 13, e1002097.

Bretscher, A., Edwards, K., and Fehon, R.G. (2002). ERM proteins and merlin: integrators at the cell cortex. Nat Rev Mol Cell Biol 3, 586-599.

$19,8066-8074$. 
626 Cortes, J.C., Carnero, E., Ishiguro, J., Sanchez, Y., Duran, A., and Ribas, J.C. (2005).

627 The novel fission yeast $(1,3)$ beta-D-glucan synthase catalytic subunit Bgs $4 p$ is

628 essential during both cytokinesis and polarized growth. J Cell Sci 118, 157-174.

629 Csikasz-Nagy, A., Gyorffy, B., Alt, W., Tyson, J.J., and Novak, B. (2008). Spatial

630 controls for growth zone formation during the fission yeast cell cycle. Yeast 25, 59-

63169.

632 Das, M., Drake, T., Wiley, D.J., Buchwald, P., Vavylonis, D., and Verde, F. (2012).

633 Oscillatory dynamics of Cdc42 GTPase in the control of polarized growth. Science $634337,239-243$.

635 Das, M., Nunez, I., Rodriguez, M., Wiley, D.J., Rodriguez, J., Sarkeshik, A., Yates, 636 J.R., 3rd, Buchwald, P., and Verde, F. (2015). Phosphorylation-dependent inhibition 637 of Cdc42 GEF Gef1 by $14-3-3$ protein $\operatorname{Rad} 24$ spatially regulates Cdc42 GTPase 638 activity and oscillatory dynamics during cell morphogenesis. Molecular biology of the 639 cell $26,3520-3534$.

640 Dodgson, J., Chessel, A., Yamamoto, M., Vaggi, F., Cox, S., Rosten, E., Albrecht, D., 641 Geymonat, M., Csikasz-Nagy, A., Sato, M., et al. (2013). Spatial segregation of 642 polarity factors into distinct cortical clusters is required for cell polarity control. $643 \quad$ Nature communications 4, 1834.

644 Elowitz, M.B., and Leibler, S. (2000). A synthetic oscillatory network of 645 transcriptional regulators. Nature 403, 335-338.

646 Fievet, B.T., Gautreau, A., Roy, C., Del Maestro, L., Mangeat, P., Louvard, D., and 647 Arpin, M. (2004). Phosphoinositide binding and phosphorylation act sequentially in 648 the activation mechanism of ezrin. J Cell Biol 164, 653-659.

649 Foiani, M., Marini, F., Gamba, D., Lucchini, G., and Plevani, P. (1994). The B 650 subunit of the DNA polymerase alpha-primase complex in Saccharomyces cerevisiae 
651 executes an essential function at the initial stage of DNA replication. Mol Cell Biol $652 \quad 14,923-933$.

653 Garcia, P., Tajadura, V., Garcia, I., and Sanchez, Y. (2006). Role of Rho GTPases and 654 Rho-GEFs in the regulation of cell shape and integrity in fission yeast. Yeast 23, 655 1031-1043.

656 Geymonat, M., Spanos, A., and Sedgwick, S.G. (2007). A Saccharomyces cerevisiae 657 autoselection system for optimised recombinant protein expression. Gene 399, 120$658 \quad 128$.

659 Gierer, A., and Meinhard.H (1972). Theory of Biological Pattern Formation. 660 Kybernetik 12, 30-39.

661 Goryachev, A.B., and Pokhilko, A.V. (2008). Dynamics of Cdc42 network embodies 662 a Turing-type mechanism of yeast cell polarity. FEBS letters 582, 1437-1443.

663 Hipfner, D.R., Keller, N., and Cohen, S.M. (2004). Slik Sterile-20 kinase regulates 664 Moesin activity to promote epithelial integrity during tissue growth. Genes Dev 18, $665 \quad 2243-2248$

666 Hirao, M., Sato, N., Kondo, T., Yonemura, S., Monden, M., Sasaki, T., Takai, Y., and 667 Tsukita, S. (1996). Regulation mechanism of ERM (ezrin/radixin/moesin) 668 protein/plasma membrane association: possible involvement of phosphatidylinositol 669 turnover and Rho-dependent signaling pathway. J Cell Biol 135, 37-51.

670 Huang, N.E., Shen, Z., Long, S.R., Wu, M.L.C., Shih, H.H., Zheng, Q.N., Yen, N.C., 671 Tung, C.C., and Liu, H.H. (1998). The empirical mode decomposition and the Hilbert 672 spectrum for nonlinear and non-stationary time series analysis. Proceedings of the 673 Royal Society a-Mathematical Physical and Engineering Sciences 454, 903-995. 
674 Huang, T.Y., Markley, N.A., and Young, D. (2003). Nak1, an essential germinal

675 center (GC) kinase regulates cell morphology and growth in Schizosaccharomyces

676 pombe. J Biol Chem 278, 991-997.

677 Huisman, S.M., and Brunner, D. (2011). Cell polarity in fission yeast: a matter of 678 confining, positioning, and switching growth zones. Semin Cell Dev Biol 22, 799679805.

680 Kelly, F.D., and Nurse, P. (2011). Spatial control of Cdc42 activation determines cell 681 width in fission yeast. Molecular biology of the cell 22, 3801-3811.

682 Kissil, J.L., Johnson, K.C., Eckman, M.S., and Jacks, T. (2002). Merlin 683 phosphorylation by p21-activated kinase 2 and effects of phosphorylation on merlin 684 localization. J Biol Chem 277, 10394-10399.

685 Knaus, U.G., Heyworth, P.G., Evans, T., Curnutte, J.T., and Bokoch, G.M. (1991). 686 Regulation of phagocyte oxygen radical production by the GTP-binding protein Rac 687 2. Science $254,1512-1515$.

688 Kuo, C.C., Savage, N.S., Chen, H., Wu, C.F., Zyla, T.R., and Lew, D.J. (2014). 689 Inhibitory GEF Phosphorylation Provides Negative Feedback in the Yeast Polarity 690 Circuit. Curr Biol 24, 753-759.

691 Matsuyama, A., Arai, R., Yashiroda, Y., Shirai, A., Kamata, A., Sekido, S., 692 Kobayashi, Y., Hashimoto, A., Hamamoto, M., Hiraoka, Y., et al. (2006). ORFeome 693 cloning and global analysis of protein localization in the fission yeast 694 Schizosaccharomyces pombe. Nat Biotechnol 24, 841-847.

695 Mitchison, J.M., and Nurse, P. (1985). Growth in cell length in the fission yeast 696 Schizosaccharomyces pombe. J Cell Sci 75, 357-376.

697 Moreno, S., Klar, A., and Nurse, P. (1991). Molecular genetic analysis of fission yeast 698 Schizosaccharomyces pombe. Methods Enzymol 194, 795-823. 
699 Nakamura, F., Amieva, M.R., and Furthmayr, H. (1995). Phosphorylation of

700 threonine 558 in the carboxyl-terminal actin-binding domain of moesin by thrombin

701 activation of human platelets. J Biol Chem 270,31377-31385.

702 Neisch, A.L., Formstecher, E., and Fehon, R.G. (2013). Conundrum, an ARHGAP18

703 orthologue, regulates RhoA and proliferation through interactions with Moesin. Mol

704 Biol Cell 24, 1420-1433.

705 Niccoli, T., Arellano, M., and Nurse, P. (2003). Role of Tea1p, Tea3p and Pom1p in

706 the determination of cell ends in Schizosaccharomyces pombe. Yeast 20, 1349-1358.

707 Novak, B., and Tyson, J.J. (2008). Design principles of biochemical oscillators.

708 Nature reviews Molecular cell biology 9, 981-991.

709 Pietromonaco, S.F., Simons, P.C., Altman, A., and Elias, L. (1998). Protein kinase C-

710 theta phosphorylation of moesin in the actin-binding sequence. J Biol Chem 273, $7117594-7603$.

712 Qyang, Y., Yang, P., Du, H., Lai, H., Kim, H., and Marcus, S. (2002). The p21713 activated kinase, Shk1, is required for proper regulation of microtubule dynamics in 714 the fission yeast, Schizosaccharomyces pombe. Mol Microbiol 44, 325-334.

715 Rincon, S.A., Estravis, M., and Perez, P. (2014). Cdc42 regulates polarized growth 716 and cell integrity in fission yeast. Biochemical Society transactions 42, 201-205.

717 Rothbauer, U., Zolghadr, K., Muyldermans, S., Schepers, A., Cardoso, M.C., and 718 Leonhardt, H. (2008). A versatile nanotrap for biochemical and functional studies 719 with fluorescent fusion proteins. Mol Cell Proteomics 7, 282-289.

720 Rupes, I., Jia, Z., and Young, P.G. (1999). Ssp1 promotes actin depolymerization and 721 is involved in stress response and new end take-off control in fission yeast. Mol Biol 722 Cell 10, 1495-1510. 
723 Shaw, R.J., Paez, J.G., Curto, M., Yaktine, A., Pruitt, W.M., Saotome, I., O'Bryan,

724 J.P., Gupta, V., Ratner, N., Der, C.J., et al. (2001). The Nf2 tumor suppressor, merlin,

725 functions in Rac-dependent signaling. Dev Cell 1, 63-72.

726 Snaith, H.A., Samejima, I., and Sawin, K.E. (2005). Multistep and multimode cortical 727 anchoring of tealp at cell tips in fission yeast. Embo J 24, 3690-3699.

728 Snaith, H.A., and Sawin, K.E. (2003). Fission yeast mod5p regulates polarized growth

729 through anchoring of tea1p at cell tips. Nature 423, 647-651.

730 Speck, O., Hughes, S.C., Noren, N.K., Kulikauskas, R.M., and Fehon, R.G. (2003).

731 Moesin functions antagonistically to the Rho pathway to maintain epithelial integrity.

732 Nature 421, 83-87.

733 Thadani, R., Huang, D., and Oliferenko, S. (2011). Robust polarity specification 734 operates above a threshold of microtubule dynamicity. Cytoskeleton (Hoboken) 68, $735 \quad 290-299$.

736 Turing, A.M. (1952). The Chemical Basis of Morphogenesis. Philosophical 737 Transactions of the Royal Society of London Series B-Biological Sciences 237, 37$738 \quad 72$.

739 Wilson-Grady, J.T., Villen, J., and Gygi, S.P. (2008). Phosphoproteome analysis of

740 fission yeast. Journal of proteome research 7, 1088-1097.

741 Yonemura, S., Matsui, T., and Tsukita, S. (2002). Rho-dependent and -independent 742 activation mechanisms of ezrin/radixin/moesin proteins: an essential role for 743 polyphosphoinositides in vivo. J Cell Sci 115, 2569-2580. 
Figures

Figure 1. Tea3 is a local inhibitor of Cdc42 activity at growing cell domains.

748 (A) Left, A Tea3-GFP RFP-Bgs4 co-expressing cell imaged every 10 minutes and the

749 main polarized growth transitions (OETO, NETO and septation) it undergoes. Middle,

750 Fluorescence intensity profiles of Tea3 (green) and Bgs4 (red) along the cell axis

751 during those transitions. Right, Tea3 (green) and Bgs4 (red) maximal fluorescence

752 intensities at the 'old end' and 'new end' through the cell cycle. Note that Tea3

753 counter-mirrors growth. (B) Quantification of maximal Scd1-GFP and Scd2-GFP

754 fluorescence at growing end of monopolar wild-type (WT), rgfl $\Delta$ and tea3 $\Delta$ cells co-

755 expressing Scd1-GFP or Scd2-GFP and RFP-Bgs4cells ( $\mathrm{n}>50$ cells/condition). (C)

756 Images of monopolar wild-type (WT), rgfl $\Delta$ and tea3 $\Delta$ cells co-expressing Scd2-GFP

757 and RFP-Bgs4. (D) Quantification of maximal RFP-Bgs4 fluorescence at growing end

758 of monopolar wild-type (WT) and tea3A cells co-expressing Scd1-GFP and RFP-

759 Bgs4cells ( $>50$ cells/condition). (E) Images of cells co-expressing Tea3-GBP-

760 mCherry and Rga4-GFP or Cdr2-GFP. Arrows denote lack of Tea3-GBP-mCherry at

761 the new cell end in the presence of Rga4-GFP or Cdr2-GFP; arrowhead denotes

762 relocalisation of Tea3-GBP-mCherry to the cell middle in the presence of Cdr2-GFP.

763 (F) Proportion of monopolar and bipolar cells in exponential cultures with indicated

764 genotypes. Septated cells and cells prior to OETO have not been considered. Average

765 of 2 independent experiments with $\mathrm{n}>150$ cells/condition. Error bars represent \pm SD.

766 Scalebars: $5 \mu \mathrm{m}$ 
Figure 1-figure supplement 1

771 (A) Quantification of the Tea3-GBP localisation at the growing and non-growing cell

772 ends in cells expressing Tea3-GBP-mCherry alone or in combination with Rga4-GFP

773 or Cdr2-GFP. $n=20$ cells per condition. Error bars represent \pm SD. (B) Images of cells

774 expressing Tea3-GBP and cytosolic GFP. Cell end localisation of the GFP can be

775 observed in cells with a septum, where concentration of Tea3 is high at the cell ends,

776 but not in bipolar cells where concentration of Tea3 at the cell ends is low. (C)

777 Quantification of the intensity of Cdr2-GFP and Rga4-GFP at the non-growing cell

778 ends in strains expressing Tea3-GBP alone or in combination with Tea3-ProA. $\mathrm{n}=20$

779 cells per condition. Error bars represent \pm SD. (D) Western blot of crude extract

780 derived from strains RCS517, M146 and M147, to show the expression of the Tea3-

781 ProA allele. The upper part of the blot has been probed with a Rabbit Peroxidase anti-

782 Peroxidase antibody (Sigma P1291) and the lower part with a monoclonal anti-tubulin

783 antibody. (E, F) Quantification of the intensity of Scd2-GFP in WT (E) and tea3 $\triangle$ (F)

784 cells in monopolar cells plotted versus the length of the cell. The data demonstrate

785 that there is no increased concentration of Scd2-GFP in longer monopolar cells. 
A
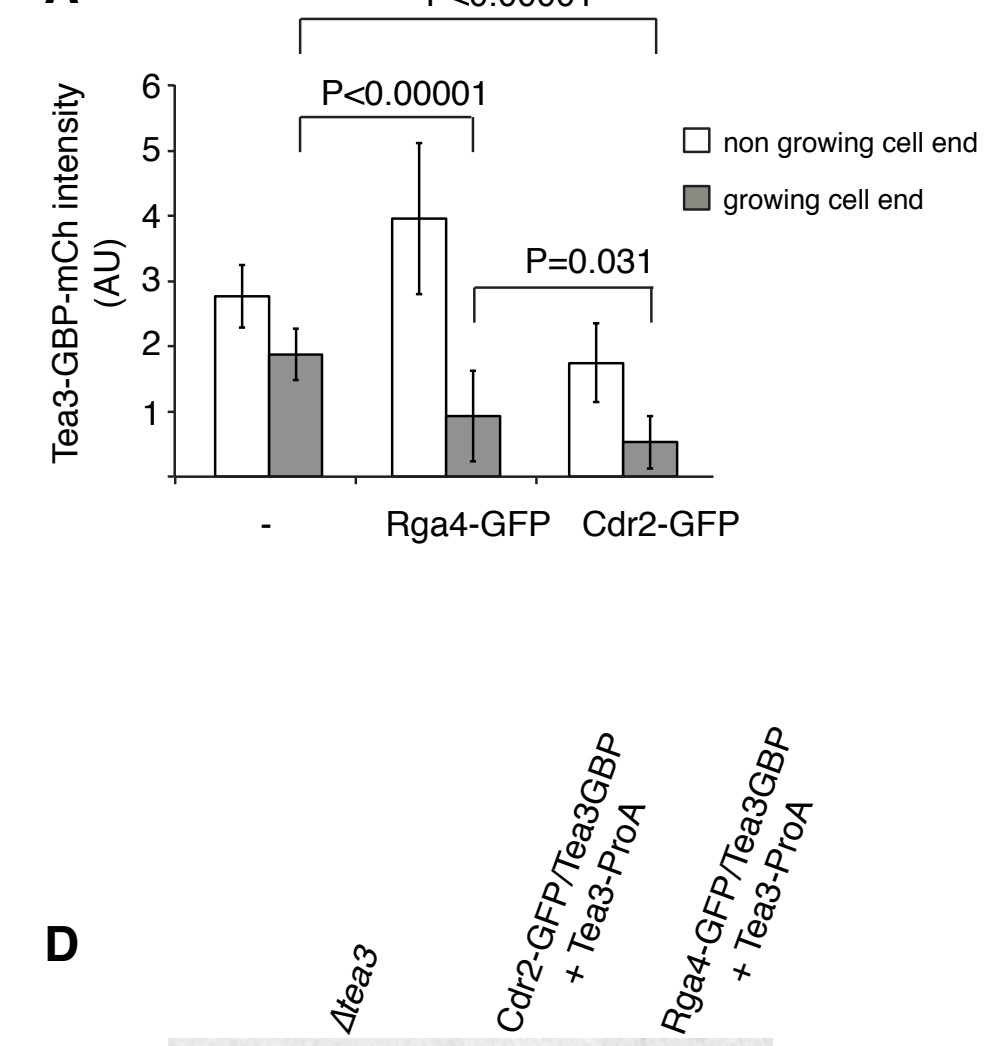

Tea3-ProA -

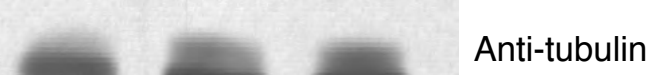

B

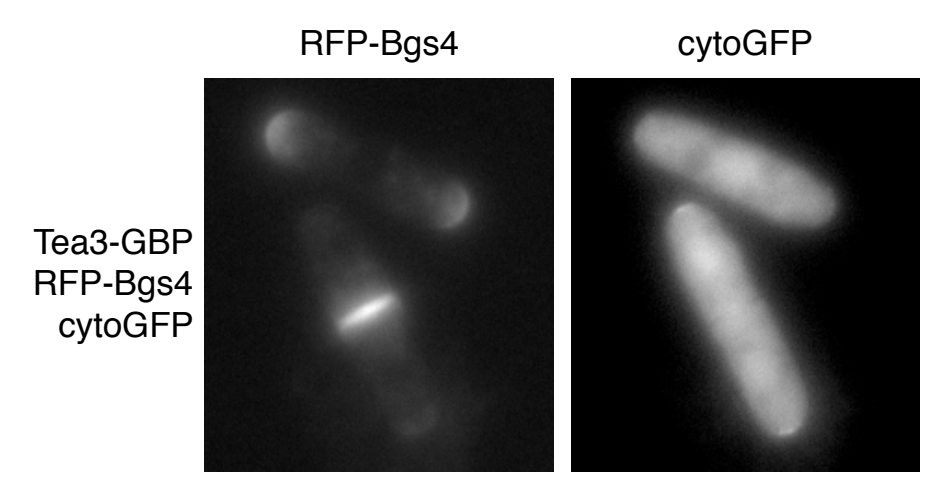

E

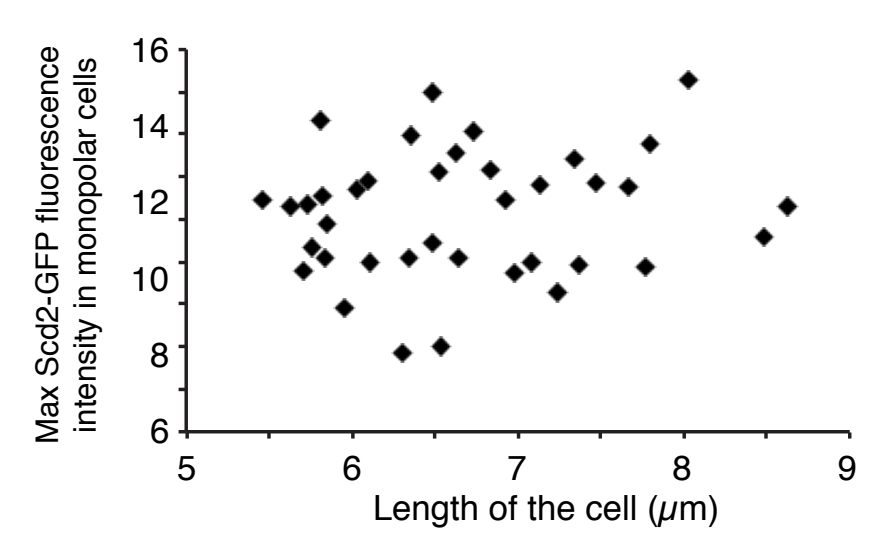

C

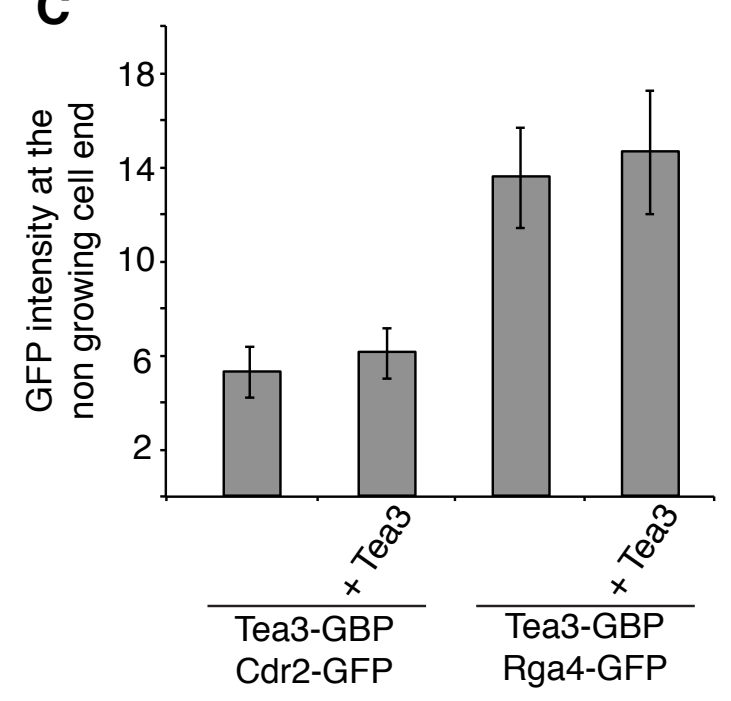

F

$\Delta t e a 3$

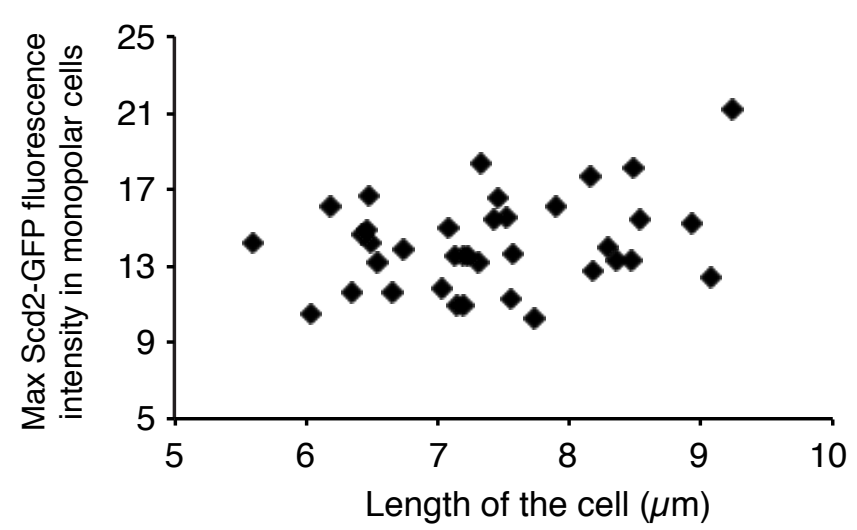


bioRxiv preprint doi: https://doi.org/10.1101/402990; this version posted August 29, 2018. The copyright holder for this preprint (which was

not certified by peer review) is the author/funder, who has granted bioRxiv a license to display the preprint in perpetuity. It is made available under aCC-BY-NC-ND 4.0 International license.

04

Figure 2. Tea3 function is phosphorylation-dependent and under control by the

\section{PAK kinase Shk1.}

(A) Anti-GFP antibody Western blot of Tea3-GFP immunoprecipitated from Tea3GFP-expressing cycling (left), cdc10-129 G1-arrested (middle) and cdc25-22 G2arrested (right) cells, treated with or without $\lambda$-PPase. (B) Anti-GFP antibody Western blot of Tea3-GFP from cells of the indicated backgrounds. (C) Anti-Tea3 antibody Western blot from cells of the indicated backgrounds. Phos-tag containing 6\% acrylamide gel. (D) Quantification of Tea3-GFP and Tea3-6A-GFP fluorescence intensity at the cell ends in monopolar, bipolar and septating cells, classified based on their RFP-Bgs4 localization ( $\mathrm{n}>50$ cells/condition were measured except bipolar Tea3-6A-GFP cells where $n=20$, as they were very rare; error bars represent \pm SD). (E) Example images of cells used for the quantifications in D. Arrows indicate bipolar cells. (F) Relative percentages of monopolar and bipolar cells in the cell lines indicated. Average of 2 experiments with $n>130$ cells/condition. Error bars represent \pm SD. Scalebars: $5 \mu \mathrm{m}$. 


\section{Figure 2-figure supplement 1}

808 Cell cycle arrest and release of the strain RCS312 (cdc25-22, Tea3-GFP). Cells were

809 arrested for $3 \mathrm{~h}$ at $37^{\circ} \mathrm{C}$ then released at $23^{\circ} \mathrm{C}$. Samples of cells were taken every 15

810 minutes for TCA extraction and septum staining. Upper panel: septation index during

811 time. Lower panel: SDS-PAGE (6\% acrylamide) of crude extract stained with an anti812 GFP antibody.

813

814 


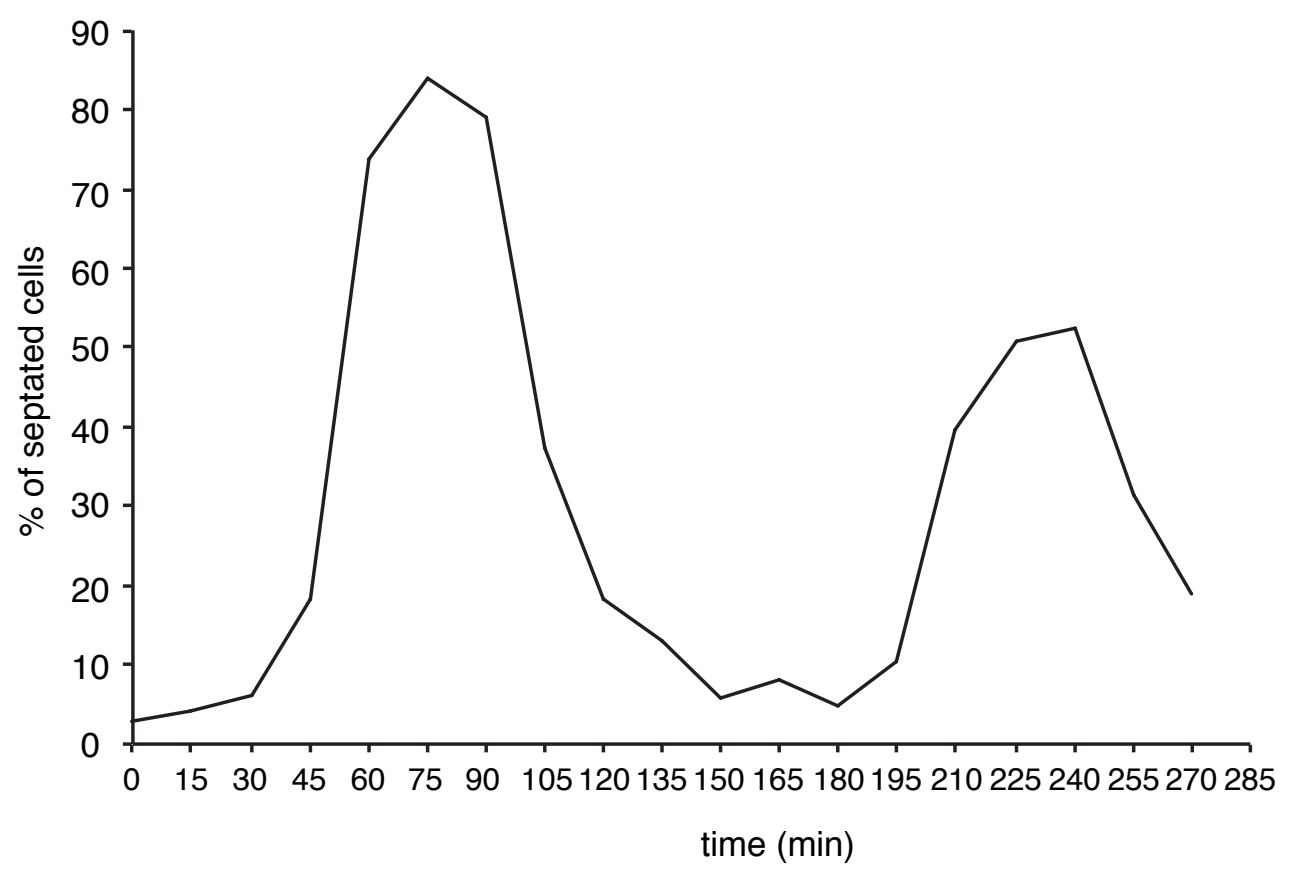

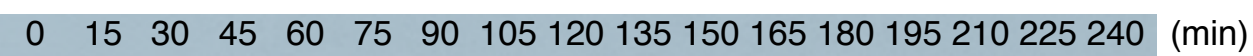

Tea3-GFP

Geymonat et al. Figure 2-figure supplement 1 
bioRxiv preprint doi: https://doi.org/10.1101/402990; this version posted August 29, 2018. The copyright holder for this preprint (which was

not certified by peer review) is the author/funder, who has granted bioRxiv a license to display the preprint in perpetuity. It is made available under aCC-BY-NC-ND 4.0 International license.

\section{Figure 2-figure supplement 2}

817 The expression of Tea3WT-GFP and Tea3-6A-GFP is comparable. $70 \mu \mathrm{g}$ of crude

818 extract from exponentially growing M7 and M37 cells were run on a gel and stained

819 with anti-GFP (upper panel) or anti-tubulin (lower panel) antibody.

820

821 


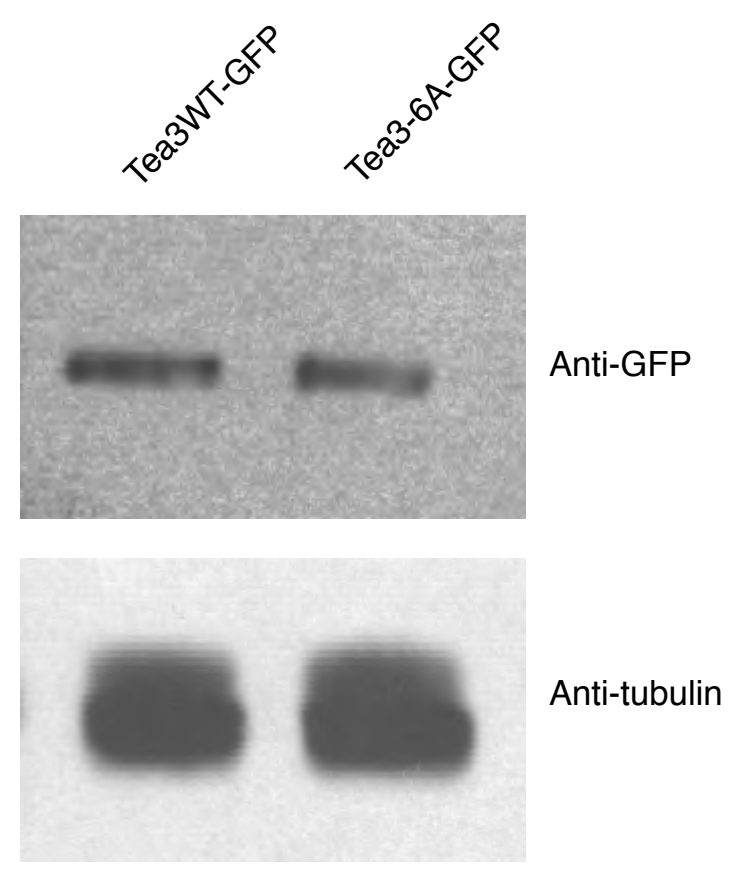

Geymonat et al. Figure 2-figure supplement 2 
823

824

825

826

828

Figure 3. Tea3 is a substrate of Shk1 in vitro and it competes with Sed2 for Shk1

\section{binding in vitro and in vivo}

(A) Purified 6His-Tea3 binds specifically to GST-Shk1. GST only and GST-Shk1 beads incubated with purified 6His-Tea3 were subjected to SDS-PAGE and Western blot analysis. Upper panel, WB decorated with anti-6His; lower panel SDS-PAGE stained with Blue Coomassie. (B) 6His-Tea3 is an in vitro substrate of Shk1. Purified 6His-Tea3 is incubated in absence (left) or presence (right) of $10 \mathrm{mM}$ ATP with purified GST-Shk1. Proteins are subjected to SDS-PAGE and stained before with ProQ diamond (Thermo Fisher) to detect phosphor proteins (upper panel) and then with Blue Coomassie (lower panel). (C) Purified 6His-Scd2-3HA binds specifically to GST-Shk1. GST only and GST-Shk1 beads incubated with purified 6His-Scd2-3HA were subjected to SDS-PAGE and Western blot analysis. Upper panel, WB decorated with anti-HA; lower panel SDS-PAGE stained with Blue Coomassie. (D) Scd2 competes with Tea3 for Shk1 binding. 6His-Tea3/GST-Shk1 complex bound to gluthatione beads is incubated with or without 10x excess of 6His-Scd2-3HA. After extensive washing proteins are analysed by SDS-PAGE and western blotting. Upper panel, anti-Tea3 (note that this antibody recognize also GST), middle panel Blue Coomassie, lower panel anti-HA. (E) Tea3 competes with Scd2 for Shk1 binding in an ATP-dependent manner. 6His-Scd2-3HA/GST-Shk1 complex bound to gluthatione beads is incubated with or without $10 \mathrm{x}$ excess of $6 \mathrm{His}-\mathrm{Tea} 3$ in presence or absence of $10 \mathrm{mM}$ ATP. After extensive washing proteins are analysed by SDS-PAGE and western blotting. Upper panel, Blue Coomassie, lower panel anti-HA. (F) Tea3-6A cannot compete with Scd2 for Shk1 binding. 6His-Scd2-3HA/GST-Shk1 complex bound to gluthatione beads is incubated with or without 10x excess of 6His-Tea3-6A in presence or absence of $10 \mathrm{mM}$ ATP. After extensive washing proteins are analysed 
848 by SDS-PAGE and western blotting. Upper panel, Blue Coomassie, lower panel anti-

849 HA. (G) Quantification of maximal Scd2-GFP fluorescence intensity at the growing

850 ends of monopolar cells expressing wild-type Tea3 (Tea3-WT) or Tea3-6A $(n=50$

851 cells for each sample). Error bars represent \pm SD. (H) Tea3-GFP and RFP-Bgs4

852 localization in WT and $s c d 2 \Delta$ cells. Quantification of maximal Tea3-GFP

853 fluorescence at growing end of monopolar WT and $s c d 2 \Delta$ cells ( $\mathrm{n}=35$ cells). Error

854 bars represent \pm SD. (I) Scd2 competes with Tea3 for Shk1 binding in vivo. GFP-

855 Shk1 is immunoprecipitated with nano-trap magnetic beads (Chromo Tech) in WT,

856 GFP-Shk1 and GFP-Shk1 $\Delta \mathrm{scd} 2$ strains. Immunoprecipitated proteins are subjected to

857 SDS-PAGE and Western blotting using anti-Tea3 (upper panel) and anti-GFP (lower

858 panel) to detect Tea3 and FGP-Shk1 respectively.

859

860 
A

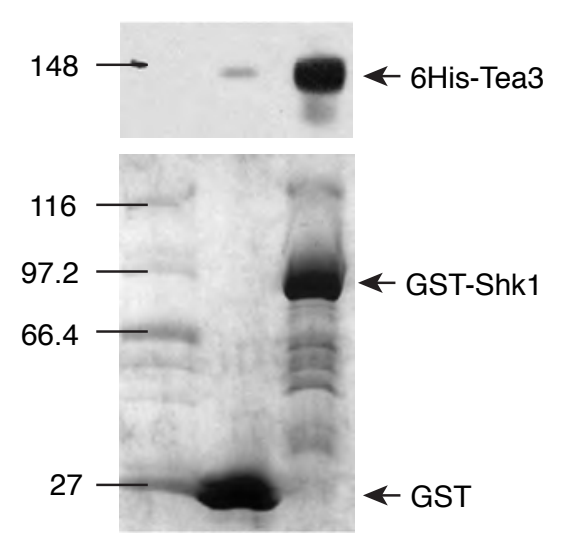

B

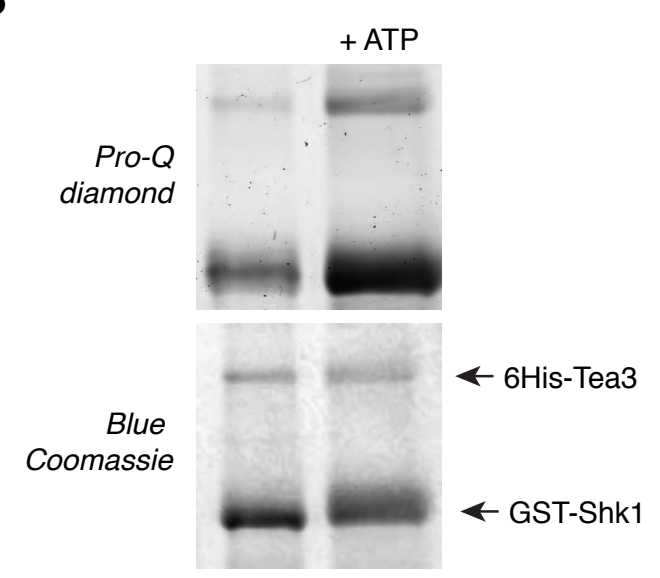

C

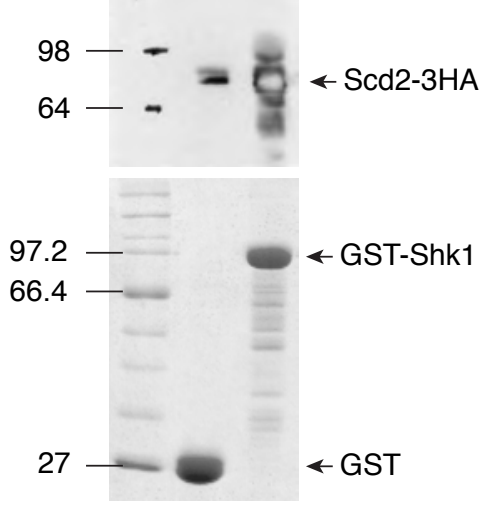

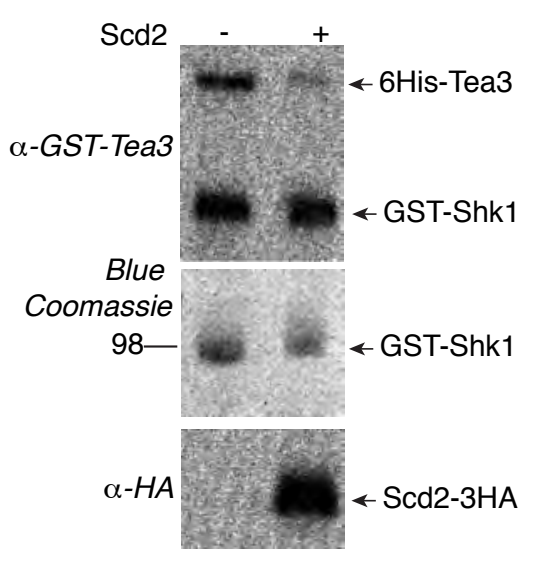

E

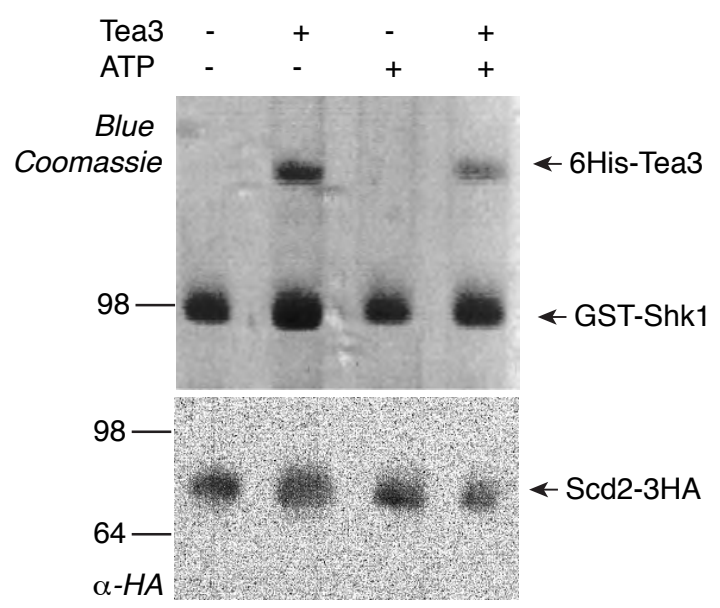

F

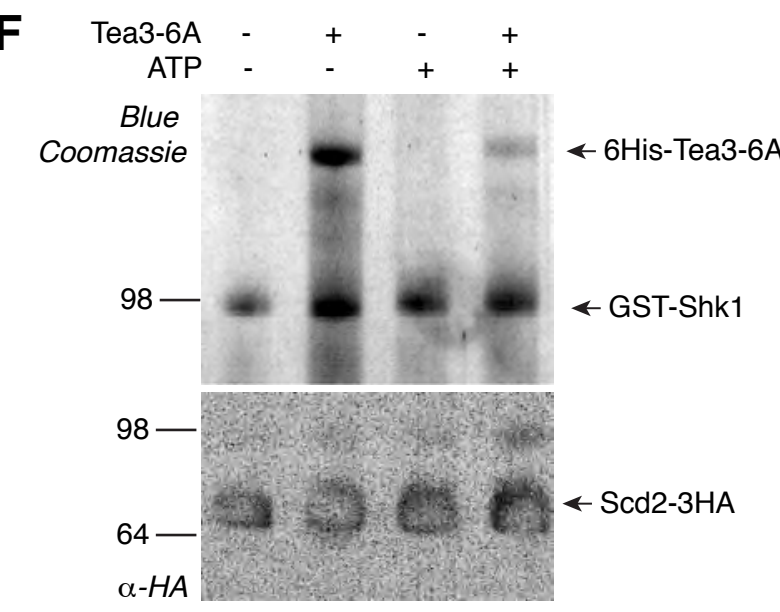

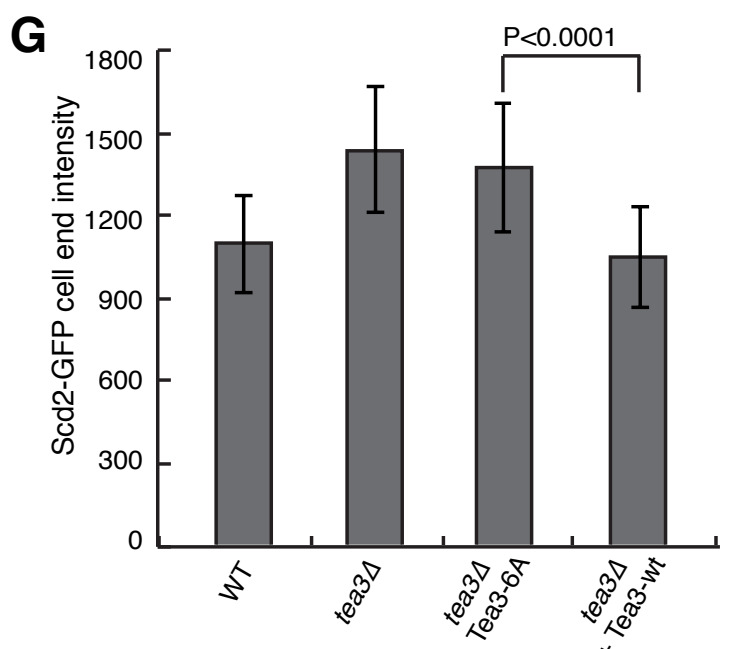
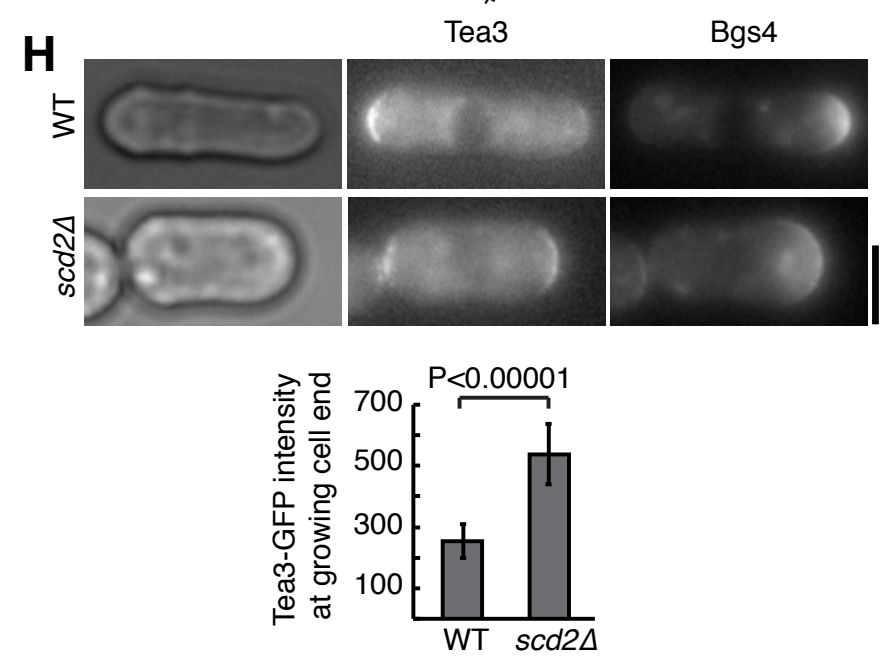

I

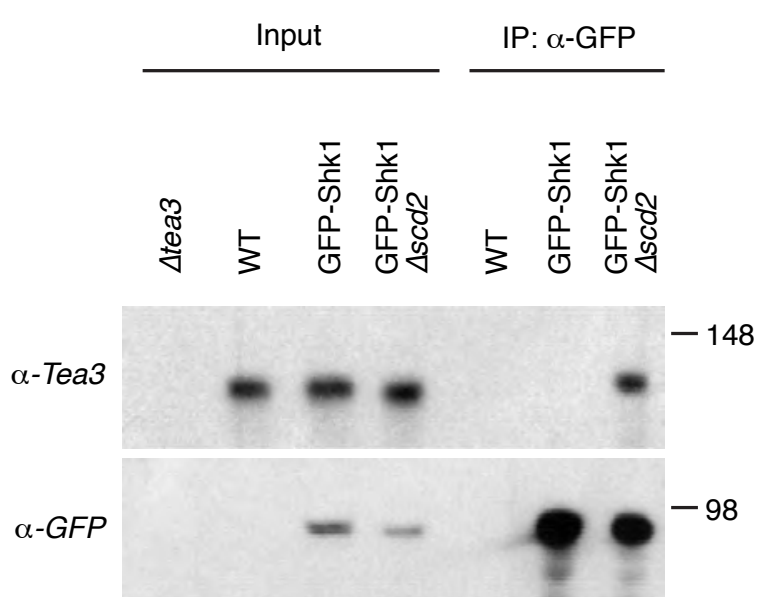

Geymonat et al. Figure 3 
Figure 4. Tea3 is integral part of the mechanism that controls cortical GTP-

864 (A) Previously described oscillatory behavior of GTP-Cdc42 at cell ends (Das et al., 865 2012), as observed using a CRIB-mCherry reporter, and newly observed oscillatory 866 behaviour of Tea3, observed via a GFP fusion. Left, timelapse fluorescence images of 867 a CRIB-mCherry Tea3-GFP co-expressing cell (note: 0' corresponds to the same real 868 timepoint in both top/bottom image sequences). Arrowheads indicate protein 869 enrichment at alternating cell ends. Right, manual quantitation of raw CRIB-mCherry 870 and Tea3-GFP signals from the cell shown on the left. Light and dark coloured lines 871 represent the fluorescence at each of the two cell ends. Note: the CRIB-mCherry and 872 Tea3-GFP image sequences and signals are from the same cell. (B) Left, Example of 873 automatically quantitated CRIB-mCherry fluorescence intensity profiles for the two 874 ends of a cell. Right, autocorrelation of each of the two cell end signals (light/dark 875 coloured lines) and cross-correlation between the signals (black line), showing a clear 876 CRIB-mCherry pattern of oscillation between the two cell ends. (C) Left, Example of 877 automatically quantitated Tea3-GFP fluorescence intensity profiles from the two ends 878 of a cell. Right: autocorrelation of each of the two cell end signals (light/dark 879 coloured lines) and cross-correlation between the signals (black line), showing a 880 Tea3-GFP pattern of oscillation between the two cell ends. (D) Distribution of CRIB 881 oscillation period values in wild-type (top left, $n=202$ ) and tea3A (bottom left, $\mathrm{n}=56$ ) 882 cells. Right: statistical significance of the difference in CRIB oscillation period 883 between wild-type and tea3 $\triangle$ cells. (E) Density plot of the cross-correlation between 884 the Tea3 and CRIB signals measured in the same cell at opposite cell ends, in a 885 population of $\mathrm{n}=202$ tracked cells co-expressing CRIB-mCherry and Tea3-GFP. Note 886 that the density is not centered around zero (which would signify uncorrelation), 
887 indicating that the CRIB and Tea3 signal oscillations in a given cell are coupled. (F)

888 Schematic model of the Shk1-dependent, Scd2-antagonizing role of Tea3 in

889 controlling activation of polarized cellular growth by locally inhibiting polarity.

890

891 

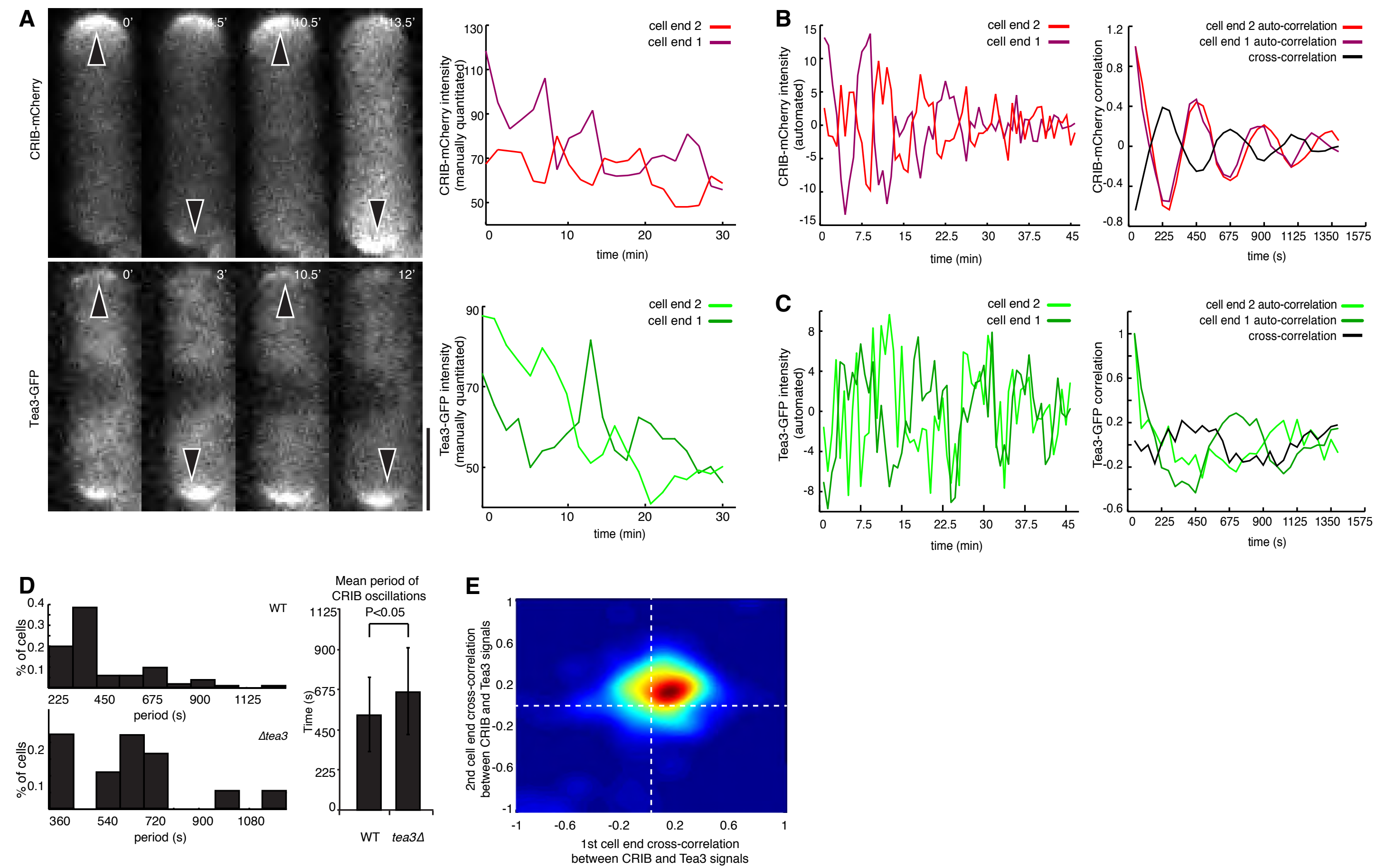
Figure 5. A Cdc42 activator-inhibitor antagonistic system simultaneously

896 (A) An activator-inhibitor model of polarity establishment in fission yeast cells.

897 Cdc42-GTP is controlled by an antagonistic 'activator' and 'inhibitor' pair, which are

898 freely diffusible and retained at cell ends by microtubule-transported landmarks.

899 Cortical, slow-diffusing activator ActC forms autocatalytically from fast diffusing

900 Act. Similarly, slow-diffusing inhibitor InhC helps its own formation from faster

901 diffusing Inh. The autocatalytic reactions are mediated by polarity 'landmark'

902 proteins and ActC inhibits the InhC feedback loop, while Inh inhibits the ActC

903 feedback loop. (B) Distribution of ActC and InhC in a 1-dimensional simulated cell.

904 ActC becomes bipolar when the length of the cell reaches $11.3 \mu \mathrm{m}$ and undergoes

905 NETO. The majority of InhC is localized at the non-growing (i.e. low Act) old end of

906 the cell pre-NETO. OE: old end; NE: new end. (C) Average level of total Act and Inh

907 in the $20 \%$ outermost region of the old and new ends of the cell in (B). (D) Removal

908 of the inhibitory effect of Inh on ActC autocatalysis $\left(k_{4}{ }^{\prime}=0 \mathrm{~min}^{-1}\right)$, as a proxy of tea 34 .

909 Act level increases at the OE and NETO happens when cells reach a longer length of

$91014.9 \mu \mathrm{m}$. (E) The experimentally observed size of cells at NETO is statistically bigger

911 in tea34 cells than in wild-type cells, as predicted by the model $(\mathrm{n}>200$

912 cells/condition; p-value <0.00005). (F) Removal of the inhibitory effect of ActC on

913 InhC autocatalysis $\left(k_{6}{ }^{\prime}=0 \mathrm{~min}^{-1}\right)$, as a proxy of $s c d 2 \Delta$. Inh level increases at the $\mathrm{OE}$

914 and NETO happens when cells reach a longer length of $14.7 \mu \mathrm{m}$. (G) Increase in the

915 background polymerization rate of Inh $\left(k_{5}{ }^{\prime}=40 \mathrm{~min}^{-1}\right)$ causes delay in NETO,

916 happening at a length of $13.9 \mu \mathrm{m}$. (H) Increase in the background polymerization rate

917 of Act $\left(k_{3}{ }^{\prime}=6.9 \mathrm{~min}^{-1}\right)$ causes advance in NETO, happening at a length of $9.15 \mu \mathrm{m}$. (I) 
918 Mimicked increase in $\mathrm{Tea} 3$ and $\mathrm{Scd} 2$ polymerization rates by inducing

919 oligomerization of the GFP-labelled proteins, using an oligomer-inducing 3GBP

920 construct confirm the timing of bipolar switch ( $\mathrm{n}=200$ cells/condition). (J)

921 Perturbation in the degradation rate of $\operatorname{Inh}\left(k_{d I n h}=0.15 \mathrm{~min}^{-1}\right)$ induces oscillations in 922 Act between the two cell ends. (K) The period of this oscillation is lengthened if Inh 923 cannot efficiently inhibit Act autocatalysis $\left(k_{4}{ }^{\prime}=70 \mathrm{~min}^{-1}\right)$; the total removal of the 924 effect of Inh would kill oscillations leading to a simulation as on panel (D). 


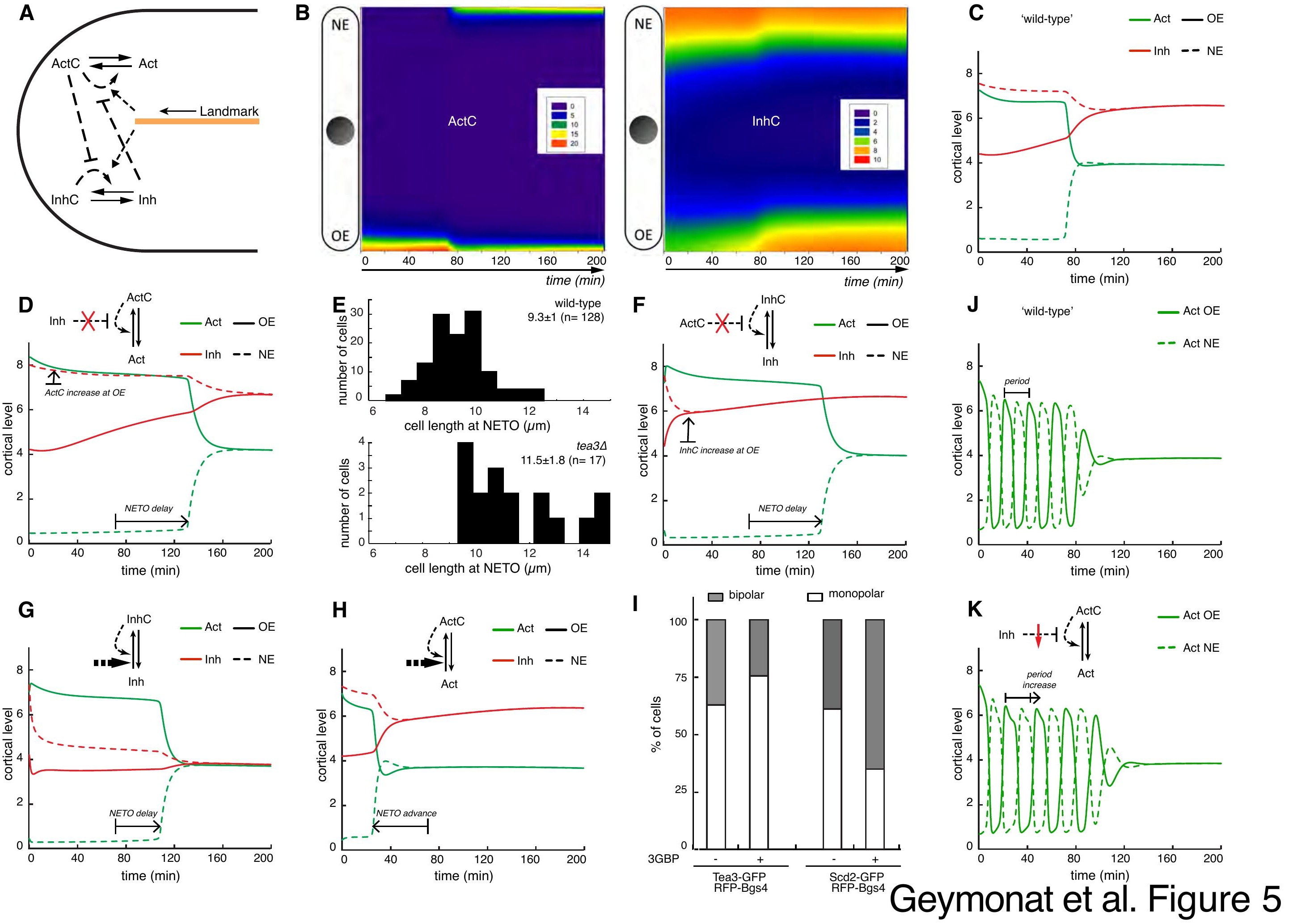


bioRxiv preprint doi: https://doi.org/10.1101/402990; this version posted August 29, 2018. The copyright holder for this preprint (which was

not certified by peer review) is the author/funder, who has granted bioRxiv a license to display the preprint in perpetuity. It is made available under aCC-BY-NC-ND 4.0 International license.

\section{Figure 5-figure supplement 1}

929 (A) Tea3 oligomerises in vivo. Tea3-GFP was immunoprecipitated from strains 930 PN556 and M156 with GFP-Trap magnetic beads. After extensive washing bound

931 proteins were analysed by SDS-PAGE and Western blotting using anti Tea3 antibody.

932 Immunoprecipitated Tea3-GFP from strain M156 (expressing also the WT allele of 933 Tea3) is able to co-purify untagged Tea3 demonstrating the ability of Tea3 to 934 oligomerise. (B) FRAP experiments using strains RCS763 and RCS774. The 935 photobleached area was half of the cell end (cortical) or inside the cytoplasm 936 (cytoplasmic). For the cortical FRAP, the recovery of fluorescence in the bleached 937 half of the cell end was followed for 1 minute with measurements every 1 second. For 938 the cytoplasmic FRAP, the recovery was followed for 3.7 seconds with measurements 939 every 54 milliseconds. The results show that there are 2 species of Tea3 and Scd2, 940 one highly dynamic in the cytoplasm and another one less dynamic associated to the 941 cortex. 
A

IP: $\alpha$-GFP

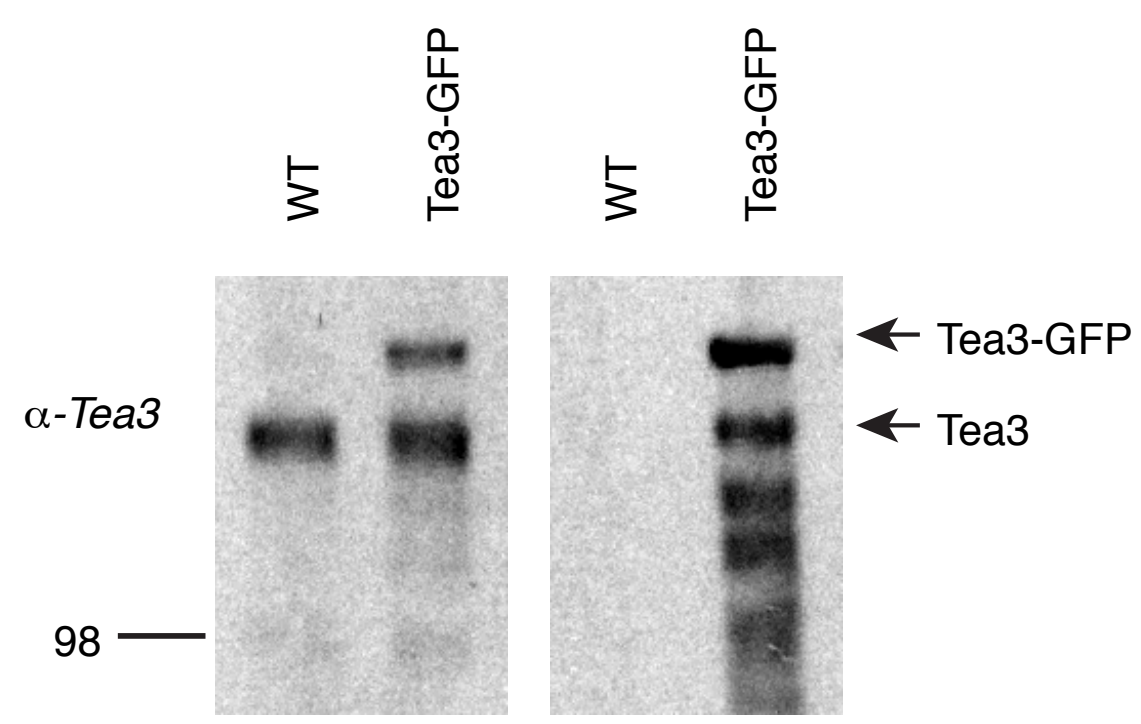

B
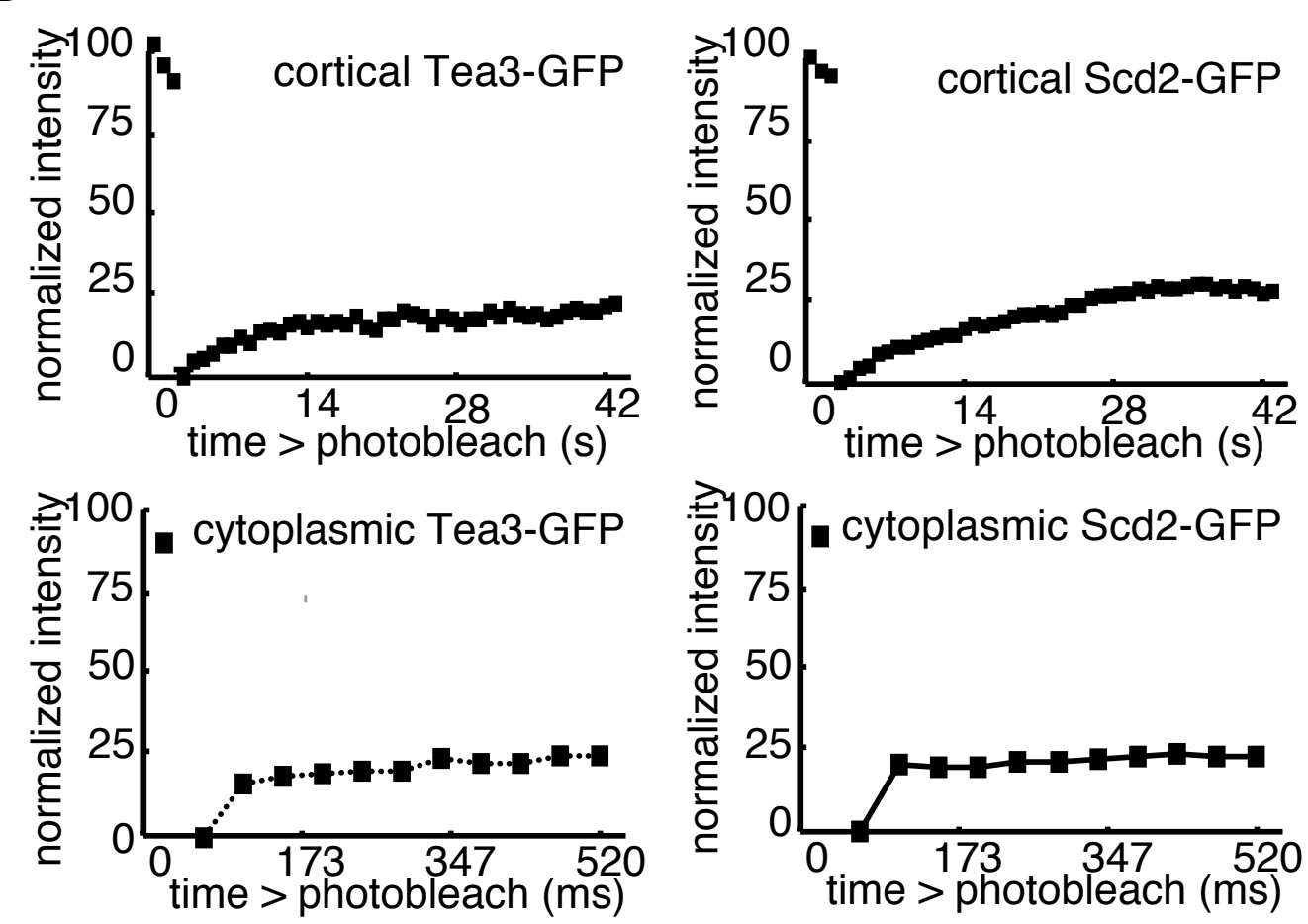


\section{Figure 5-figure supplement 2}

947 Simulations of oscillations in ActC and InhC levels when the original parameters are

948 perturbed. $(\mathbf{A}, \mathbf{B})$ Small changes in the degradation $\left(k_{d I n h}=0.15 \mathrm{~min}^{-1}\right)$ or diffusion

$949\left(D_{\text {Inh }}=240 \mu \mathrm{m}^{2} / \mathrm{min}\right)$ rates of the Tea3-like inhibitor 'Inh' can induce oscillations in

950 the cortical enrichment of both inhibitor and activator.

951

952 
A

3-fold higher Inh

egradation
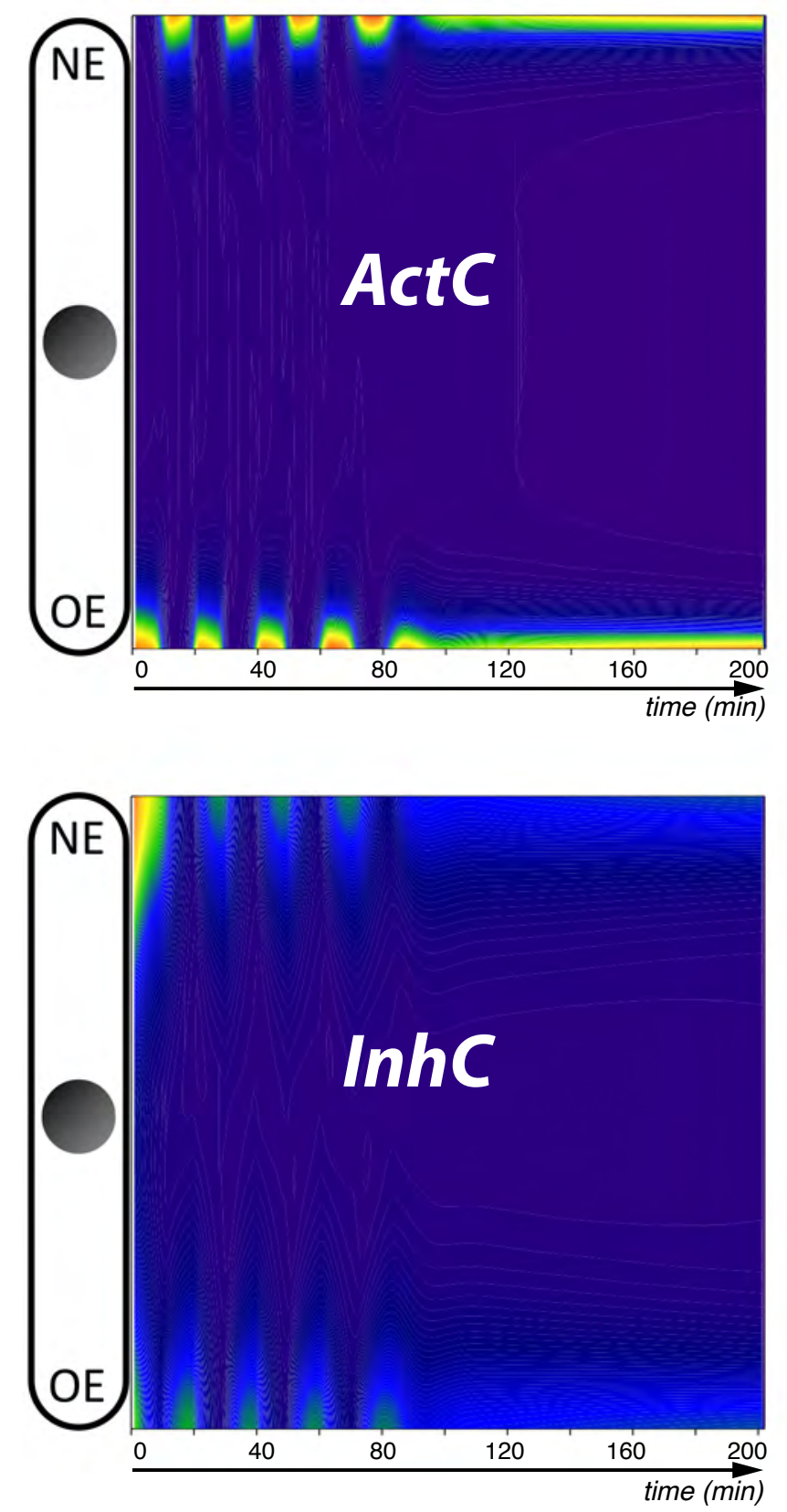

B

3-fold higher $\operatorname{Inh}_{\text {diffusion }}$
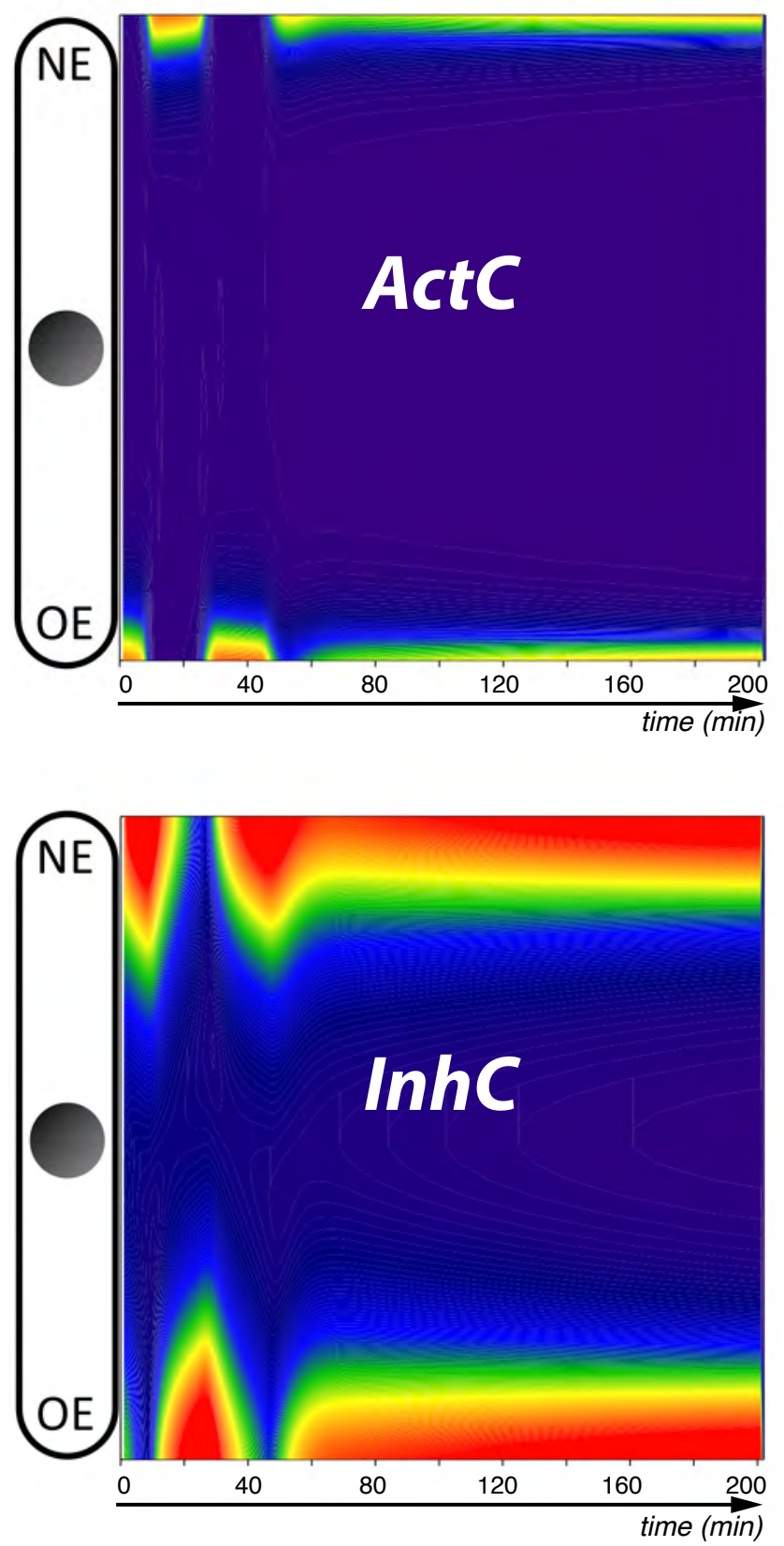

Geymonat et al. Figure 5-figure supplement 2 
bioRxiv preprint doi: https://doi.org/10.1101/402990; this version posted August 29, 2018. The copyright holder for this preprint (which was

not certified by peer review) is the author/funder, who has granted bioRxiv a license to display the preprint in perpetuity. It is made available under aCC-BY-NC-ND 4.0 International license.

954 Figure 6. A model of the mechanistic contribution of Tea3 to GTP-Cdc42

955 oscillations and the bipolar growth switch.

956

957 

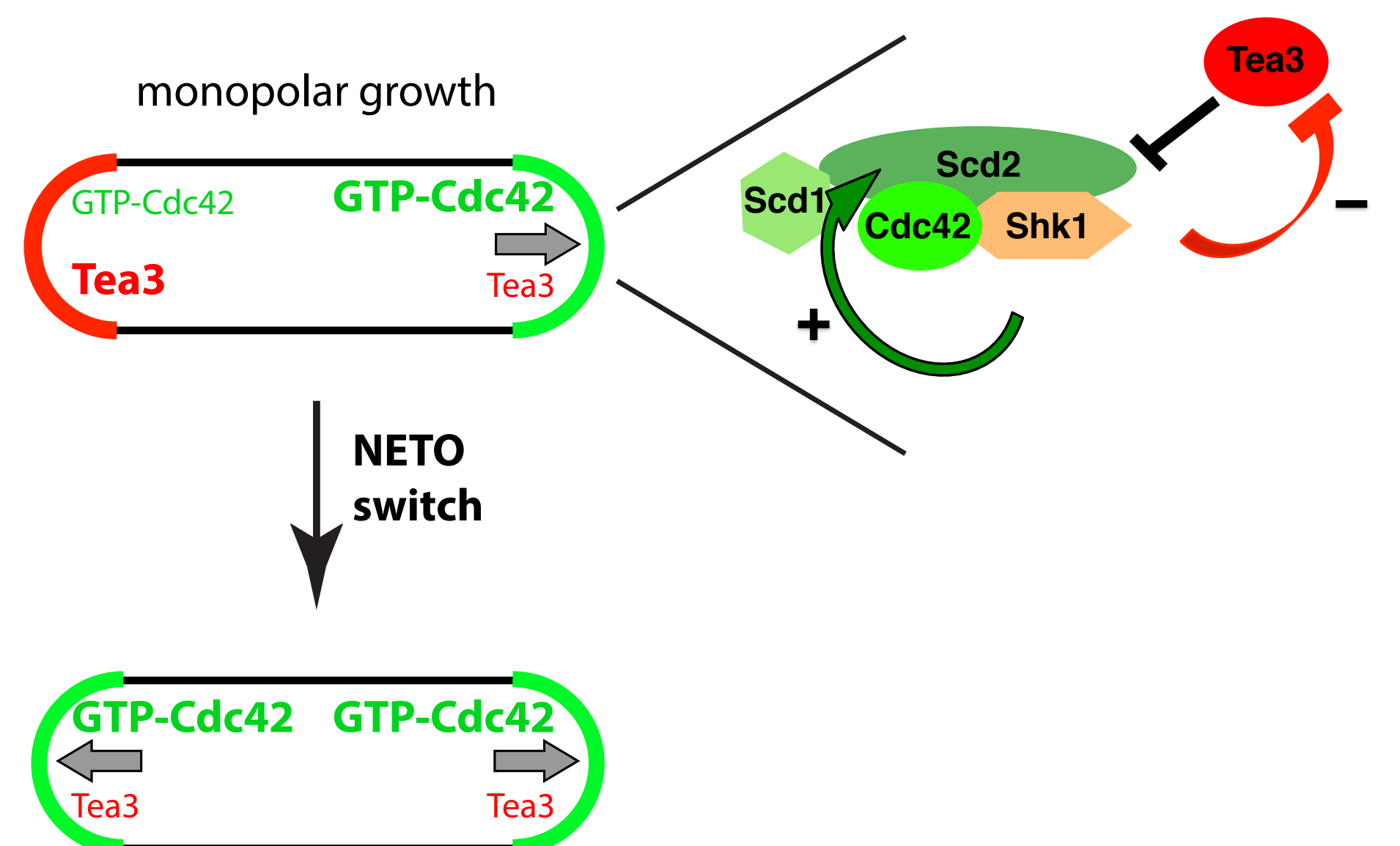

bipolar growth 
Table 1

\begin{tabular}{|c|c|c|}
\hline Strain & Genotype & Source or reference \\
\hline M19 & 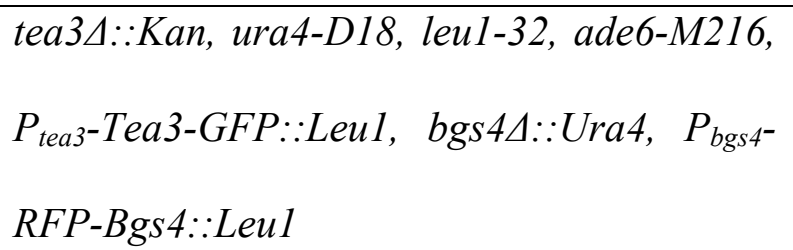 & This study \\
\hline MP18G08 & $\begin{array}{l}\text { h+; ade6-M210; leu1-32; ura4-D18; } \\
\text { mat1_m-cyhS, smt0; rpl42::cyhR (sP56Q), } \\
\text { Scd1-3GFP::Nat, bgs44::ura4, } P_{\text {bgs } 4}-R F P- \\
\text { Bgs } 4: \because H p h\end{array}$ & This study \\
\hline MP18A08 & 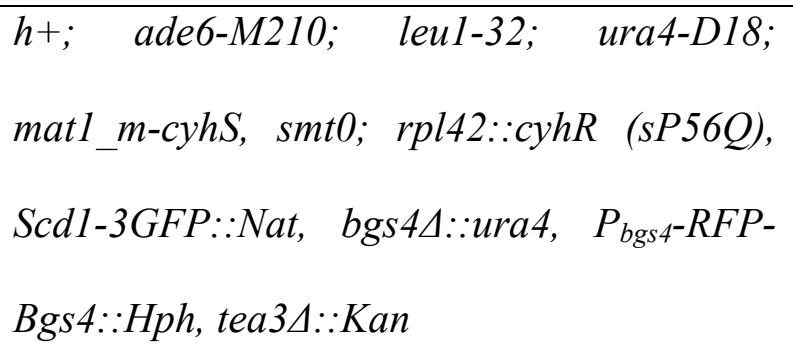 & This study \\
\hline RCS774 & $\begin{array}{l}\text { h-; ade6-M210; leu1-32; ura4-D18; } \\
\text { mat1_m-cyhS, smt0; rpl42::cyhR (sP56Q), } \\
\text { Scd2-GFP ::Nat, bgs44::ura4, } P_{\text {bgs } 4-R F P-} \\
\text { Bgs } 4: \because H p h\end{array}$ & This study \\
\hline MP05C01 & $\begin{array}{l}\text { h+; ade6-M210; leu1-32; ura4-D18; } \\
\text { mat1_m-cyhS, smt0; rpl42::cyhR (sP56Q), } \\
\text { Scd2-GFP ::Nat, bgs4A::ura4, } P_{\text {bgs } 4-R F P-} \\
\text { Bgs } 4: \because H p h, \text { rgf } 14:: \text { Kan }\end{array}$ & This study \\
\hline MP05A02 & $\begin{array}{l}\text { h+; ade6-M210; leu1-32; ura4-D18; } \\
\text { mat1_m-cyhS, smt0; rpl42::cyhR (sP56Q), } \\
\text { Scd2-GFP::Nat, bgs4A::ura4, } P_{\text {bgs } 4}-R F P- \\
\text { Bgs } 4: \because H p h, \text { tea } 3 \Delta:: \text { Kan }\end{array}$ & This study \\
\hline
\end{tabular}




\begin{tabular}{|c|c|c|}
\hline RCS763 & $\begin{array}{l}\text { h-; ade6-M210; leu1-32; ura4-D18; } \\
\text { mat1_m-cyhS, smt0; rpl42::cyhR (sP56Q), } \\
\text { Tea3-GFP::Nat, bgs4A::ura4, } P_{b_{s} 4}-R F P- \\
\text { Bgs4::Hph }\end{array}$ & This study \\
\hline MP02C12 & $\begin{array}{l}\text { h+; ade6-M210; leu1-32; ura4-D18; } \\
\text { mat1_m-cyhS, smt0; rpl42::cyhR (sP56Q), } \\
\text { Tea3-GFP::Nat, bgs } 4 \Delta: \because u r a 4, \quad P_{b g s 4}-R F P- \\
\text { Bgs } 4: \because H p h, \text { scd } 24: \because K a n\end{array}$ & This study \\
\hline MH412 & $\begin{array}{l}\text { h+, ura4-D18, leu1-32, ade6-M216, Tea3- } \\
\text { GBP-mCherry::Hph }\end{array}$ & This study \\
\hline M140 & $\begin{array}{l}\text { ura4-D18, leu1-32, ade6-M216, Tea3-GBP- } \\
\text { mCherry::Hph, Cdr2-GFP::Kan }\end{array}$ & This study \\
\hline RCS1062 & $\begin{array}{l}\text { ura4-D18, leu1-32, ade6-M216, Tea3-GBP- } \\
\text { mCherry::Hph, Rga4-GFP::Kan }\end{array}$ & This study \\
\hline RCS1071 & $\begin{array}{l}\text { ade6-M210; leu1-32; ura4-D18; Tea3- } \\
\text { GBP::Hph, bgs4A::ura4, } P_{b g s 4} \text { RFP- } \\
\text { Bgs } 4:: B s d\end{array}$ & This study \\
\hline RCS1066 & $\begin{array}{l}\text { ade6-M210; leu1-32; ura4-D18; Rga4- } \\
\text { GFP::Kan, } \text { bgs4 } \because: \text { ura4, } \quad P_{b g s 4} \text { RFP- } \\
\text { Bgs } 4: \text { Hph }\end{array}$ & This study \\
\hline RCS1067 & $\begin{array}{l}\text { ade6-M210; leu1-32; ura4-D18; Cdr2- } \\
\text { GFP::Kan, bgs4A::ura4, } P_{b g s 4} \text { RFP- } \\
\text { Bgs4::Hph }\end{array}$ & This study \\
\hline RCS1064 & $\begin{array}{l}\text { ade6-M210; leu1-32; ura4-D18; Tea3- } \\
\text { GBP::Hph, Rga4-GFP::Kan, bgs44::ura4, }\end{array}$ & This study \\
\hline
\end{tabular}




\begin{tabular}{|c|c|c|}
\hline & $P_{b g s 4}-R F P-B g s 4: \because B s d$ & \\
\hline RCS1065 & $\begin{array}{l}\text { ade6-M210; leu1-32; ura4-D18; Tea3- } \\
\text { GBP::Hph, Cdr2-GFP::Kan , bgs } 4 \Delta:: \text { ura4, } \\
P_{b g s 4}-R F P-B g s 4:: B s d\end{array}$ & This study \\
\hline RCS320 & cdc10-129, leu1-32, Tea3-GFP::Nat & This study \\
\hline RCS312 & Cdc25-22, Tea3-GFP ::Nat & This study \\
\hline RCS237 & $\begin{array}{l}\text { h-, ade6-M210, leu1-32, ura4-D18, his7, } \\
\text { Tea3-GFP::Nat, mCherry-Atb2::Hph }\end{array}$ & This study \\
\hline RCS573 & $\begin{array}{l}\text { ade6-M210, leul-32, ura4-D18, Tea3- } \\
\text { GFP::Nat, mCherry-Atb2::Hph, teals::Ura4 }\end{array}$ & This study \\
\hline RCS285 & $\begin{array}{l}\text { ade6-M210, leu1-32, ura4-D18, Tea3- } \\
\text { GFP ::Nat, mod5A::Kan }\end{array}$ & This study \\
\hline RCS297 & $\begin{array}{l}\text { h-, ade6-M210, leu1-32, ura4-D18, Tea3- } \\
\text { GFP::Nat, mod54::Kan, tea14::Ura4 }\end{array}$ & This study \\
\hline M7 & $\begin{array}{l}h+, \text { tea3A::Kan, ura4-D18, leu1-32, ade6- } \\
\text { M216, } P_{\text {tea3 }- \text { Tea3-GFP }: \text { Leu } 1}\end{array}$ & This study \\
\hline M37 & $\begin{array}{l}h+, \text { tea3 } \because: \text { Kan, ura4-D18, leu1-32, ade6- } \\
\text { M216, } P_{\text {tea }- \text {-Tea3-6A-GFP }: \text { Leu1 }}\end{array}$ & This study \\
\hline RCS734 & $\begin{array}{l}\text { ade6-M210, leu1-32, ura4-D18, } \bmod 54: \because N a t \text {, } \\
\text { kin1 }:: \text { Kan }\end{array}$ & This study \\
\hline $\begin{array}{l}\text { nmt1- } \\
\text { shk1K415R }\end{array}$ & $\begin{array}{l}\text { h90, shk1::Ura4:: } P_{n m t 1}-\operatorname{shk} 1 K 415 R-A D E 2, \\
\text { ade6-M210, leu1-32, ura4-D18 }\end{array}$ & (Qyang et al., 2002) \\
\hline TYH1 & $\begin{array}{l}h+, \text { ade6-M210, leu1-32, ura4-D18, Ura4:: } \\
P_{n m t 1}-N a k 1\end{array}$ & (Huang et al., 2003) \\
\hline
\end{tabular}




\begin{tabular}{|c|c|c|}
\hline PN556 & $h+$, ade6-M210, leu1-32, ura4-D18 & Paul Nurse's lab \\
\hline M102 & $\begin{array}{l}\text { MATa, ura3-1, trp1-28, leu2A0, lys2, his7, } \\
\text { mob1::kanR pep } 4: \because L E U 2 / \text { pMH919-Tea3 }\end{array}$ & $\begin{array}{l}\text { S. cerevisiae } \\
\text { This study }\end{array}$ \\
\hline M104 & $\begin{array}{l}\text { MATa, ura3-1, trp1-28, leu2A0, lys } 2, \text { his } 7, \\
\text { mob1::kanR pep } 4: \because L E U 2 / \text { pMH919-Tea3-6A }\end{array}$ & $\begin{array}{l}\text { S. cerevisiae } \\
\text { This study }\end{array}$ \\
\hline M150 & $\begin{array}{l}\text { MATa, ura3-1, trp1-28, leu2A0, lys2, his7, } \\
\text { mob1::kanR pep } 4: \because L E U 2 / \text { pMG1-Shk1 }\end{array}$ & $\begin{array}{l}\text { S. cerevisiae } \\
\text { This study }\end{array}$ \\
\hline M152 & 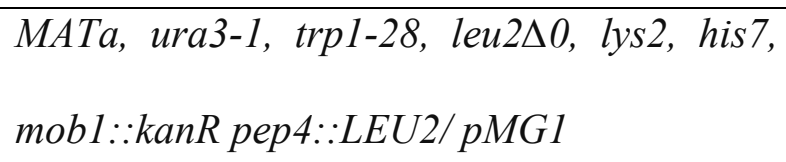 & $\begin{array}{l}\text { S. cerevisiae } \\
\text { This study }\end{array}$ \\
\hline M153 & $\begin{array}{l}\text { MATa, ura3-1, trp1-28, leu2A0, lys2, his7, } \\
\text { mob1::kanR pep4::LEU2/ pMH919-Scd2- } \\
\text { 3HA }\end{array}$ & $\begin{array}{l}\text { S. cerevisiae } \\
\text { This study }\end{array}$ \\
\hline M146 & $\begin{array}{l}\text { ade6-M210; leul-32; ura4-D18; Tea3- } \\
\text { GBP::Hph, Rga4-GFP::Kan, bgs44::ura4, } \\
P_{\text {bgs } 4-R F P-B g s 4:: B s d, P_{\text {tea3 }} \text {-Tea3-ProA::Leu1 }}\end{array}$ & This study \\
\hline M147 & $\begin{array}{l}\text { ade6-M210; leu1-32; ura4-D18; Tea3- } \\
\text { GBP::Hph, Cdr2-GFP::Kan , bgs44::ura4, } \\
P_{\text {bgs } 4-R F P-B g s 4:: B s d, P_{\text {tea3 }} \text {-Tea3-ProA::Leu1 }}\end{array}$ & This study \\
\hline M148 & $\begin{array}{l}\text { ade6-M210; leul-32; ura4-D18; Tea3- } \\
\text { GBP::Hph, bgs44::ura4, } P_{b_{g s} 4-R F P-} \\
\text { Bgs4::Leu1, P Phk1-cytosolic GFP::Leu1 }\end{array}$ & This study \\
\hline M149 & $\begin{array}{l}h+, \text { tea3 } 3:: \text { Kan, ura4-D18, leu1-32, ade6- } \\
M 216, \text { bgs } 4 \Delta:: \text { ura } 4, \quad P_{b g s}-R F P-B g s 4:: H p h, \\
P_{\text {tea3 }} \text {-Tea3-6A-GFP ::Leu1 }\end{array}$ & This study \\
\hline M141 & $h+; \quad$ ade6-M210; leu1-32; & This study \\
\hline
\end{tabular}




\begin{tabular}{|c|c|c|}
\hline & $\begin{array}{l}\text { mat1_m-cyhS, smt0; rpl42::cyhR (sP56Q), } \\
\text { Scd2-GFP::Nat, bgs4 } \because: \text { ura4, } \\
\text { Bgs4::Hph, tea34::Kan, } P_{\text {bgs } 4}-R F P- \\
\text { mCherry }: \text { Leul }\end{array}$ & \\
\hline M142 & 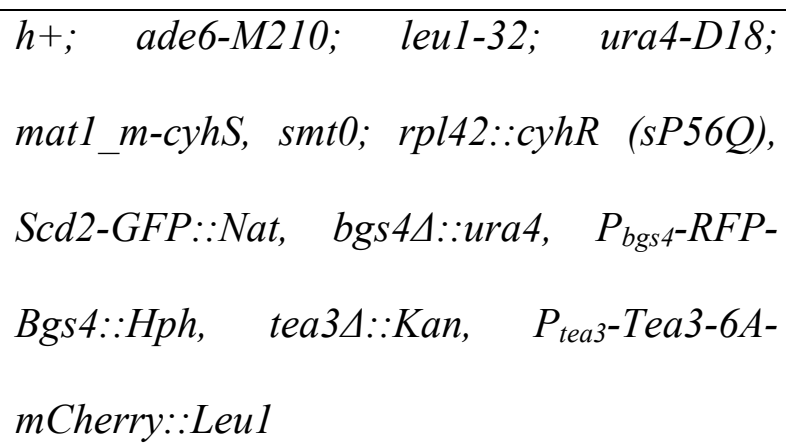 & This study \\
\hline RCS517 & tea34::Kan & Bioneer collection \\
\hline MH374 & $\begin{array}{l}\text { h-; ade6-M216; his7; leu1-32; ura4-D18; } \\
\text { nat-Pnmt41-GFP-Shk1 }\end{array}$ & This study \\
\hline MP11C06 & 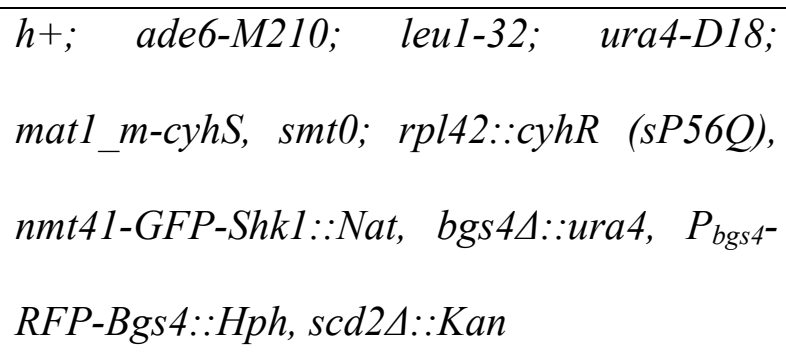 & This study \\
\hline M156 & $\begin{array}{l}\text { ura4-D18, leu1-32, ade6-M216, } P_{\text {tea3 }} \text { Tea3- } \\
\text { GFP::Leu1 }\end{array}$ & This study \\
\hline
\end{tabular}

